\title{
Module design and fault diagnosis in electric vehicle batteries
}

\author{
Gregory. J. Offer*, Vladimir. Yufit, David. A. Howey', Billy. Wu and Nigel. P. Brandon \\ Department of Earth Science Engineering \\ Imperial College London \\ London \\ United Kingdom \\ SW7 2AZ \\ * Correspondence author = gregory.offer@imperial.ac.uk, +44 (0)20 75945018 \\ v.yufit@imperial.ac.uk \\ d.howey@imperial.ac.uk \\ billy.wu06@imperial.ac.uk \\ n.brandon@imperial.ac.uk \\ 'Present address of David A. Howey \\ david.howey@eng.ox.ac.uk \\ Department of Engineering Science \\ University of Oxford \\ Oxford OX1 3PJ
}

\begin{abstract}
Systems integration issues, such as electrical and thermal design and management of full battery packs - often containing hundreds of cells - have been rarely explored in the academic literature. In this paper we discuss the design and construction of a $9 \mathrm{kWh}$ battery pack for a motorsports application. The pack contained 504 lithium cells arranged into 2 sidepods, each containing 3 modules, with each module in a 12P7S configuration. This paper focuses particularly on testing the full battery pack and diagnosing subsequent problems related to cells being connected in parallel. We demonstrate how a full vehicle test can be used to identify malfunctioning strings of cells for further investigation. After individual cell testing it was concluded that a single high inter-cell contact resistance was causing currents to flow unevenly within the pack, leading to cells being unequally worked. This is supported by a Matlab/Simulink model of one battery module, including contact resistances. Over time the unequal current flowing through cells can lead to significant differences in cells' state of charge and open circuit voltages, large currents flowing between cells even when the load is disconnected, cells discharging and aging more quickly than others, and jeopardise capacity and lifetime of the pack.
\end{abstract}

Keywords: Electric vehicle, battery pack, lithium battery, fault finding, battery management

\section{Introduction}

Electric and hybrid vehicles depend on electrochemical battery systems, with lithium-ion chemistries widely accepted as the current state of the art in terms of energy density and performance. Research and development into new electrode and electrolyte materials and chemistries continues 
apace. However, the electrical, mechanical and thermal integration of cells into packs and packs into electrical vehicles is paramount in order to ensure long and safe operation. Such integration issues have been relatively poorly researched in the literature to date. Whilst there are papers exploring the electrical and thermal behaviour of individual cells under a variety of conditions [1-5], the monitoring and testing of individual cells in battery packs $[6,7]$, and the thermal management of battery packs [4, 8-10], there are few which look at the electrical issues associated with the design and testing of complete modules, and those that do are for much lower power applications [11].

A number of factors are important in this regard. Mechanical integrity is crucial, and the challenge here given the relatively low energy densities of batteries is to minimise weight and the use of additional support materials, whilst providing adequate support and protection particularly in crash scenarios. Certain chemistries (notably $\mathrm{LiCOO}_{2}$ cathodes) are prone to dangerous 'thermal runaway' if cells are overheated, overcharged, short circuited, crushed or punctured [12], and therefore various safety mechanisms are typically incorporated at cell level, such as for example vents or deliberate delamination of the layers due to internal release of gases in an unsafe scenario [13].

In addition to ensuring the safety of vehicle occupants, the lifetime of the batteries must be maximised through the module design and battery management approach. Operating current, depth and rate of charge/discharge, and temperature all strongly affect lifetime. Batteries are particularly intolerant to temperature extremes, with high temperatures being encountered during high current loading conditions such as fast charging or acceleration transients which cause large specific internal heat generation [2]. This is primarily due to resistive heating in the contacts, electrodes and electrolyte [8]. The temperatures reached within a cell depend on the level of heat generation, the thermal properties and the heat transfer around the cell, i.e. the cooling system.

High power lithium-ion cells tend to have very low internal resistances, of the order of $m \Omega$, and the contact resistances between cells are normally measured in $\mu \Omega$ assuming connections have been made correctly. However, faulty contacts which lead to much higher contact resistances (e.g. of the order of $\mathrm{m} \Omega$ ) will adversely affect pack performance, often in unexpected ways, and this can be detected by current pulse techniques combined with individual cell testing, as described later in this paper. In parallel-connected cells, it is normally assumed that 'self balancing' will occur due to all cells being forced to the same potential [11]. However, as we later discuss, large differences in interconnection resistances in this configuration can lead to differences in the currents flowing through individual cells, which means that cells may not be well balanced under load and over time this could lead to unequal performance of individual cells. Clearly it is important to avoid this. In addition if unequal current pathways are introduced through poor design cells may become unbalanced under load.

This is conceptually a similar problem to that experienced within cells at high charge and discharge rates. One-dimensional models perpendicular to the plane of the separator/ electrolyte predict that the reactions occur at the electrode/electrolyte interfaces regardless the position of current collection tabs [8]. Under high currents however, a 1D model is not sufficient because there are spatial variations in the orthogonal directions. Indeed, 2D [5] and 3D [4] models predict that reactions preferentially occur in proximity of the current collection tabs in planar cells in the plane parallel to the separator due to noticeable ohmic drop along the current collector [4, 5]. Hence under high charge or discharge rates, large spatial variations in lithium concentration, reaction 
current density and overpotential might occur within a cell, and upon removal of the load large internal currents could flow as lithium redistribution occurs [3]. This is further compounded by thermal gradients within a cell which can also cause changes to internal resistances and lead to even greater internal spatial variations $[3,9,10]$.

The electrical behaviour of a battery can be represented by an electrical circuit model comprising of interconnected resistors, capacitors and inductors. Varying degrees of complexity are possible depending on the level of fidelity required, but the simplest modelling usually includes a series inductor, resistance $R_{i}$ and then one or two $R C$ time constant pairs (e.g. $C_{d l}$ the double layer capacitance and $R_{c t}$ the charge transfer resistance as shown) representing various dynamic effects. However, for the typical sampling rates at which battery management systems operate $(1-10 \mathrm{~Hz}$ maximum), the relevant dynamics are the instantaneous change caused by the voltage drop across the internal resistance, diffusion - with time constants of minutes to hours - and change in open circuit potential according to state of charge.

Previous authors have shown that short current pulses can be used to estimate the series resistance and other parameters of a battery system, and that the resulting current and voltage behaviour of the full pack in a real vehicle follows the model predictions reasonably accurately [14]. Indeed, in addition to traditional frequency response measurement techniques [7], pulse techniques have been used to estimate the internal resistance of lithium cells in a hybrid vehicle, and this can be used to provide a measure of battery degradation (capacity fade) over time [6].

In this paper we discuss issues associated with the design and testing of complete battery packs for electric vehicles. Secondly we explore a methodology for detecting and analysing faults in complete battery modules at the pack and vehicle testing stage, by using a current pulse (or 'current interrupt') method for pack level, and electrochemical impedance spectroscopy for cell level tests.

\section{Battery pack construction}

The battery pack used for experimental testing consisted of 504 4.8Ah (at a $0.5 \mathrm{C}$ discharge rate) Kokam Lithium-polymer pouch cells with a maximum and minimum operating voltage limit of $4.2 \mathrm{~V}$ and $2.7 \mathrm{~V}$ respectively. The cells have a rated capacity of $17.8 \mathrm{Wh}$ each and continuous discharge current of $96 \mathrm{~A}$ with a peak current of $192 \mathrm{~A}$.

These were divided into two sidepods containing 252 cells each, for use in a prototype electric racing vehicle. Each sidepod was further subdivided into three modules containing 84 cells each. The cells in each module were arranged in a 12P7S configuration, giving each module an operating voltage range of $18.9 \mathrm{~V}$ to $29.4 \mathrm{~V}$. The three modules were connected in series giving a sidepod operating voltage range of $56.7 \mathrm{~V}$ to $88.2 \mathrm{~V}$. The two battery sidepods were connected in parallel to two PM72601B Kelly Motor controllers powering two Agni 95R brushed DC motors each rated at $77 \mathrm{~V}$ maximum. The main battery specifications are shown in Table 1.

Table 1: Battery pack specifications

\begin{tabular}{ll}
\hline Maximum voltage & $88.2 \mathrm{~V}$ \\
Minimum voltage & $56.7 \mathrm{~V}$ \\
Nominal voltage & $77.7 \mathrm{~V}$ \\
Capacity & $115.2 \mathrm{Ah}$ \\
\hline
\end{tabular}




\begin{tabular}{ll}
\hline Watt hours & $8,950 \mathrm{Wh}$ \\
Continuous discharge current & $2,208 \mathrm{~A}$ \\
Peak discharge current & $4,704 \mathrm{~A}$ \\
Maximum power & $415 \mathrm{~kW}$ \\
Nominal power & $195 \mathrm{~kW}$ \\
\hline
\end{tabular}

A battery management system (BMS) produced by REAP systems Ltd., monitored the voltages and temperatures of each parallel strip of cells with a sampling rate of $1 \mathrm{~Hz}$. Each BMS board has the capability to measure 14 voltages and 7 temperatures. Voltage measurements were made at the outer point on one side of each parallel strip and temperature measurements were made in the centre of a strip where the temperature is assumed to be highest. All sensor wires were routed to the top of the module through 2x10-pin Harwin connectors and then to the BMS boards, with appropriate fusing. The BMS then communicated with a National Instruments compactRIO supervisory controller via CANbus.

The main components of the battery modules are shown in Figure 1. Two gridded polypropylene plates provided the cell support for each battery module at the centre of the cells. The mid-plates are the most structurally important part of the modules, supporting the bulk weight of the cells and provide the fundamental support structure that other elements are fixed to. Two end plates sat around the cell tabs. Aluminium bars provided the electrical connections between the individual cells.

Polypropylene T-pieces and L-pieces were used to clamp the aluminium bars as well electrically isolate them. Tie rods ran through the span of these blocks, from one T-piece to another ensuring the cell tabs were securely fastened. Along the length of the cells, pins were inserted from both sides of the module through the T-pieces, end plate and mid plates. These were held in place by threaded inserts and plastics spacers that set the distance between the plates and electrically insulated the metal pins.

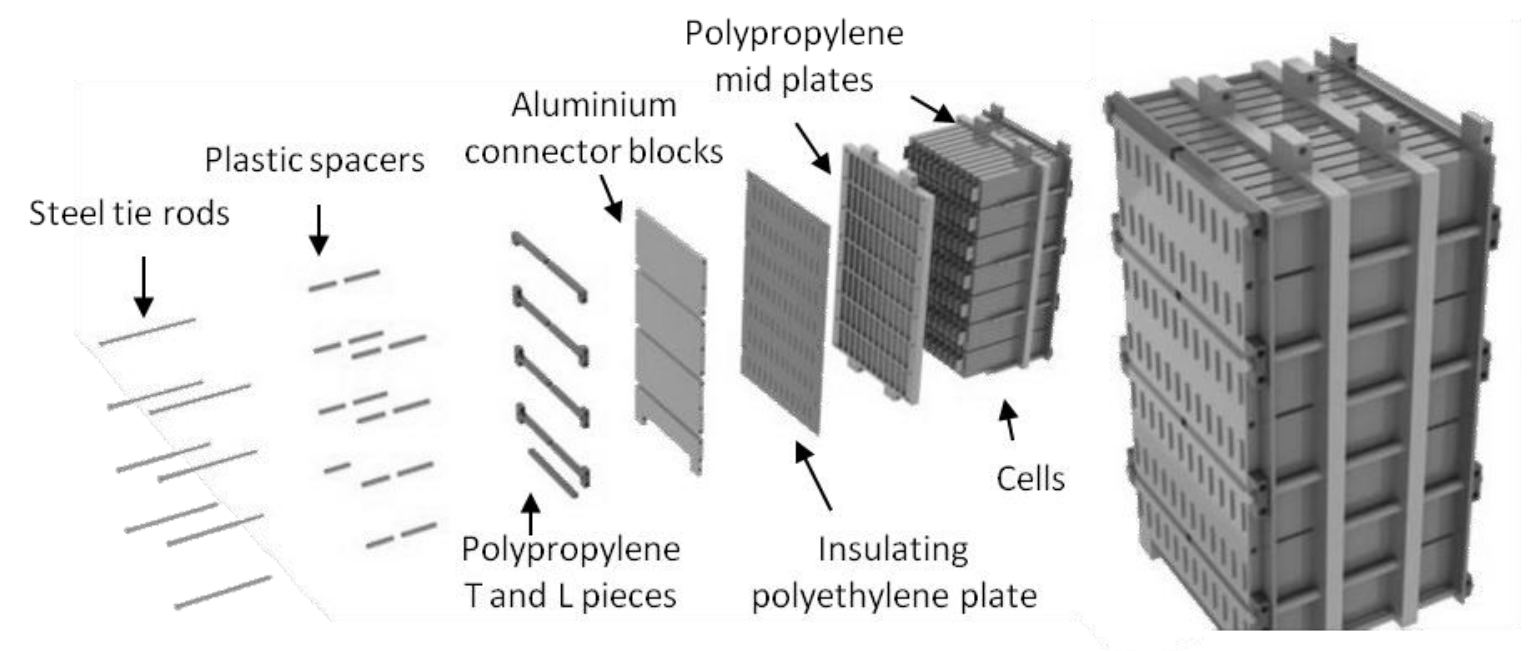

Figure 1: Exploded and fully assembled view of a battery module 
The T-pieces and L-pieces secured and aligned the aluminium connection blocks to transfer the load from the endplate to the pins and vice versa, and secure the blocks, the endplates and the pins together. The T-design allowed the blocks to be tightened together using tie rods and secured all parts adequately without restricting or inducing additional stresses. Figure 2 shows this arrangement

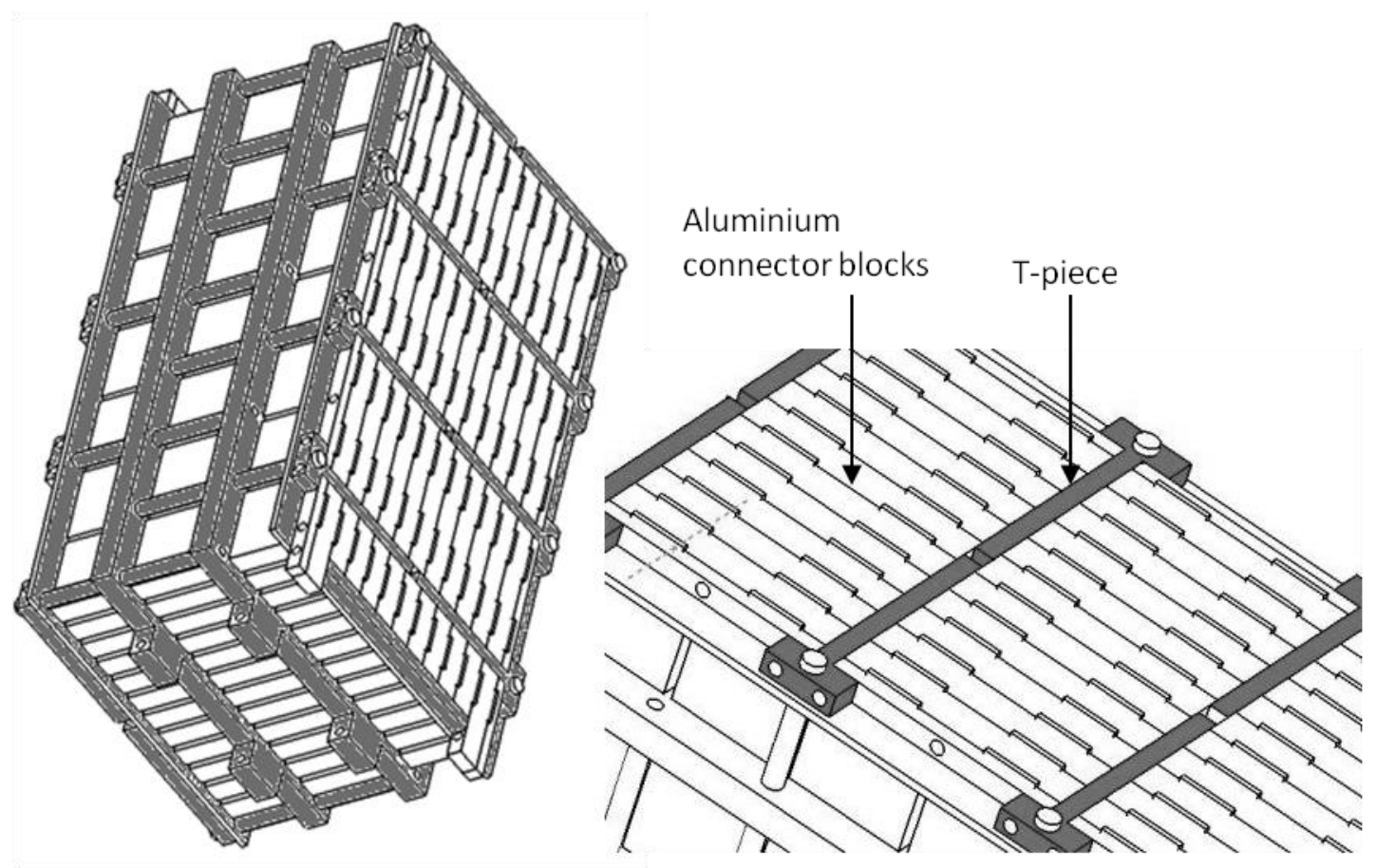

Figure 2: Polypropylene T-pieces of battery modules

The three modules were connected in series in each sidepod with electrical connections being made at the diagonal corners of the modules with bolted aluminium bars, as shown in Figure 3. Copper connectors were considered however it was shown that large contact pressures would be required for an aluminium-copper interface to be effective.

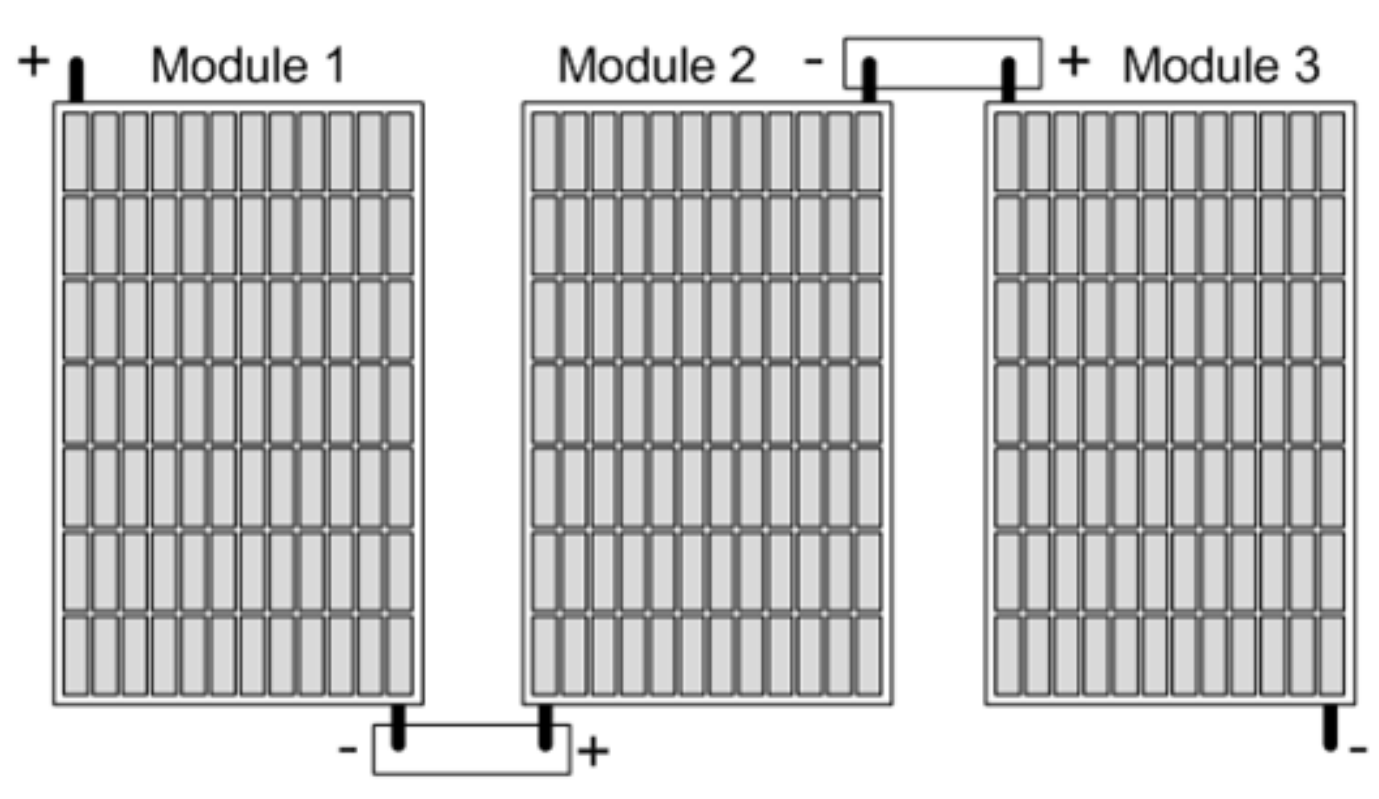

Figure 3: Battery module configuration 
Due to the connection configuration, the positive and negative terminals of the pack are at opposite ends. For the vehicle design, it was desirable to have the positive and negative terminals on the same side. Therefore, an aluminium bus bar was used to return the negative terminal to the same position as the positive terminal.

Two Gigavac GX200 contactors were also located within each sidepod. These were rated to a continuous discharge current of $400 \mathrm{~A}$ and peak of 1,980 A. A PVC box housed the three modules of each sidepod. The base was designed to be load bearing and to transmit the weight of the modules to the supporting chassis support bars. The sidepods were adhesively bonded to the chassis support bars as it was not required to be able to remove them.

\section{Module testing and fault identification}

Testing was conducted on the battery modules in the vehicle configuration, i.e. the battery modules were installed on the vehicle and battery data was recorded during vehicle testing. The purpose of the testing was not to specifically test the battery packs, but to test the entire vehicle. The testing consisted of running the vehicle on a dynamometer or 'rolling road' and included both acceleration events, i.e. brief bursts of high power, and also endurance events, i.e. continuous discharge. Neither were representative of a typical driving cycle, however they were designed to stress the vehicle under simulated conditions representing two extremes of operation.

\section{a. Acceleration test}

In the acceleration test the power was increased to $27.5 \mathrm{~kW}$ within 3 seconds, and then reduced to zero within 2 seconds. An unusually high comparative voltage drop in one of the parallel strips in module 5 was noticed, which indicated a suspected fault. The current and voltage response measured using the BMS for module 5 is shown in Figure 4.

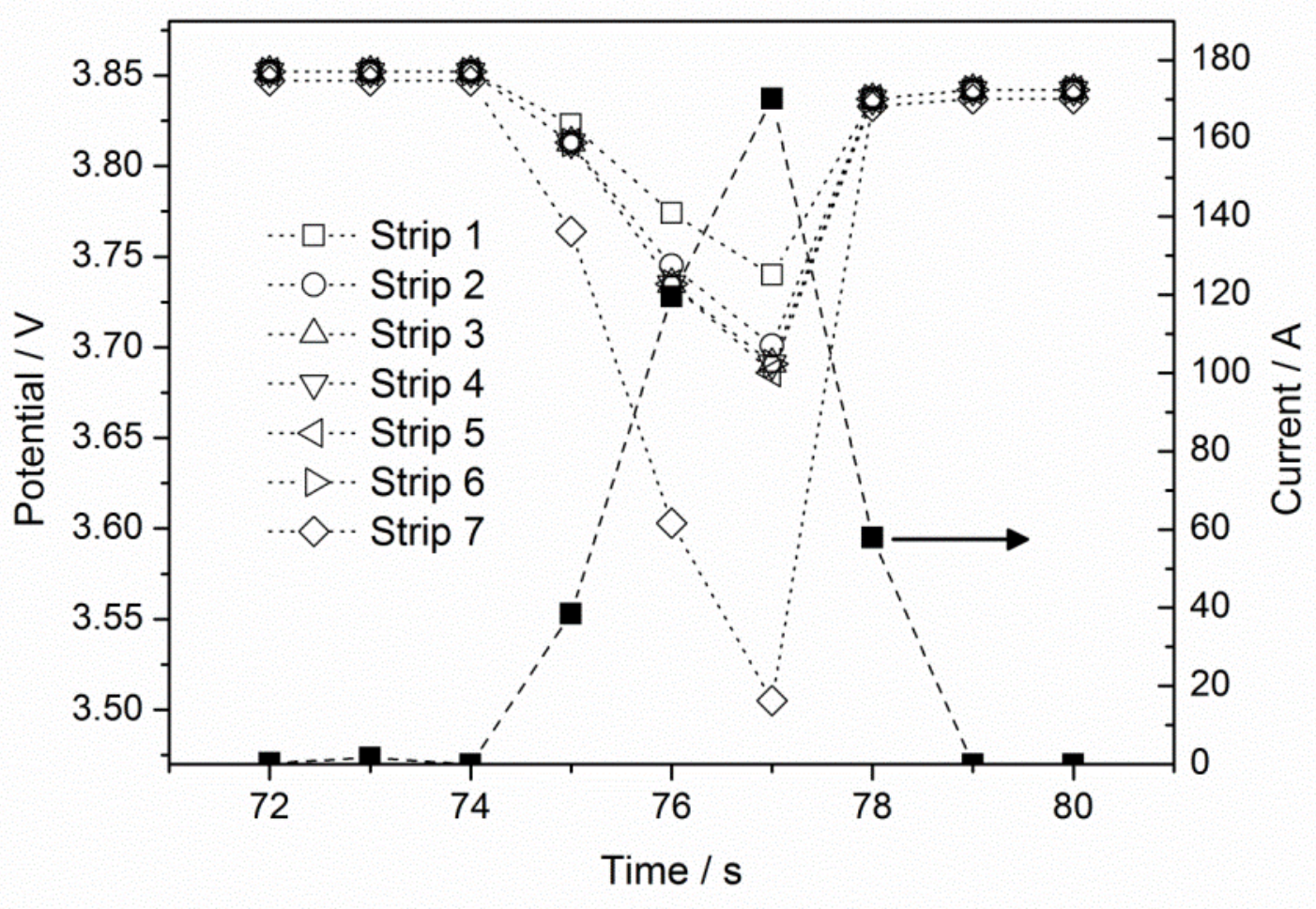


Figure 4: Test data from module 5 during a 3 second acceleration test on the dynamometer, current is shown with the axis on the right (black squares), and the voltage response of each strip of cells is shown with the axis on the left (hollow symbols)

The voltage response for every strip of cells in every module at the time stamp with the highest current at 77s compared to the open circuit potential is shown in Figure 5.

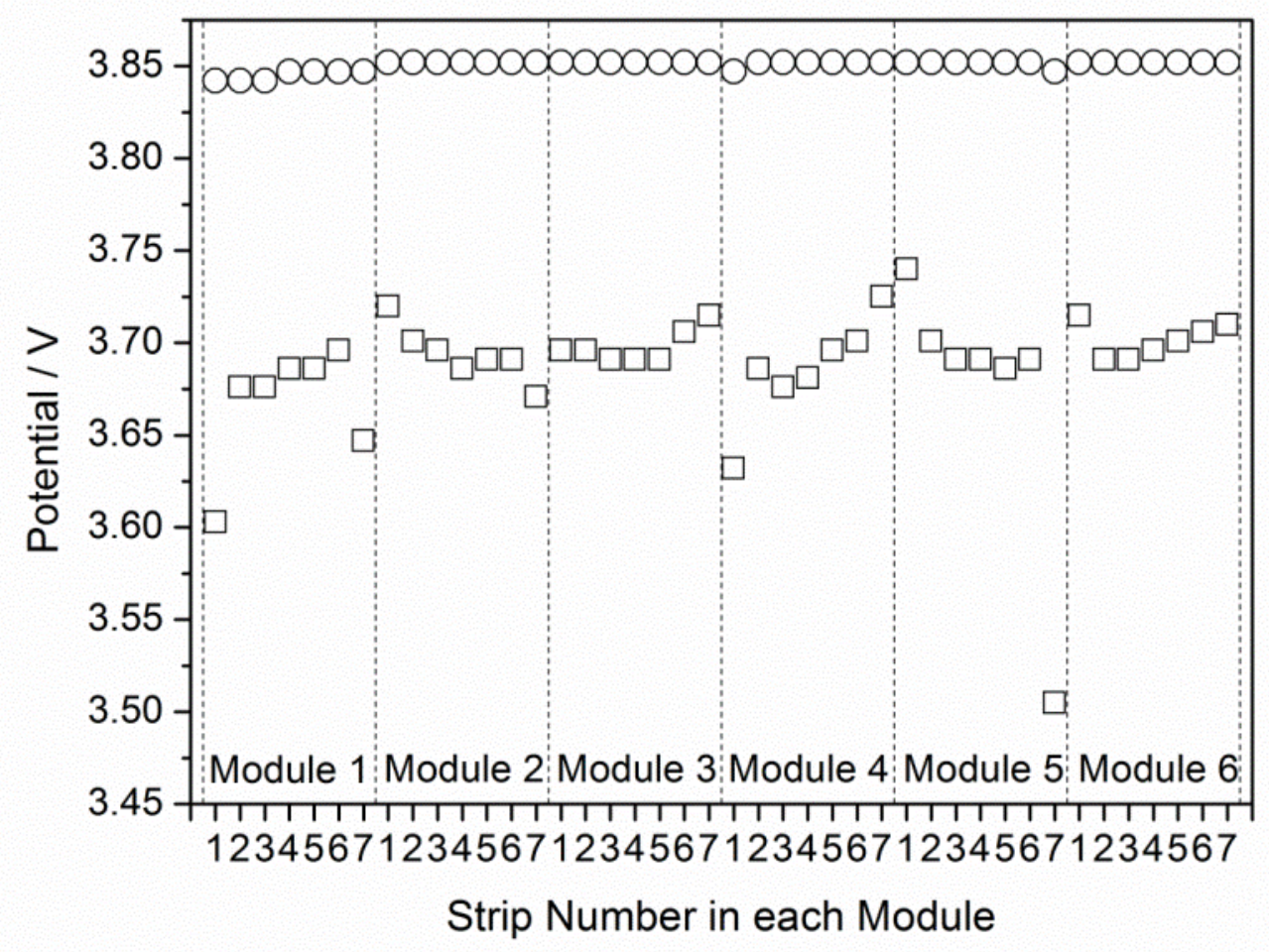

Figure 5: Test data from all modules during a 3 second acceleration test on the dynamometer, the voltage response at 77s (hollow squares) and the open circuit potential (hollow circles) is shown for all strips in all modules

As can clearly be seen in Figure 5, strip 7 in module 5 has a significantly lower voltage under load than any other strip in any other module, yet the open circuit potential of all strips in all modules are not significantly different. This was considered to be indicative of a fault.

The acceleration test can be likened to a current interrupt event, and therefore the data can be used to calculate a differential resistance $R$ using the equation $R=\Delta V / \Delta /$ between time stamp 77 and 78 where $\mathrm{R}$ is the differential resistance for a 1 second current interrupt, shown in Figure 6 . This effectively lumps any processes with a frequency response of less than $1 \mathrm{~Hz}$ including all series resistances into a single resistance measurement. In practice this means that for a lithium-ion cell every dynamic process except diffusion and instantaneous ohmic voltage drop is not seen at this sampling rate [15]. 


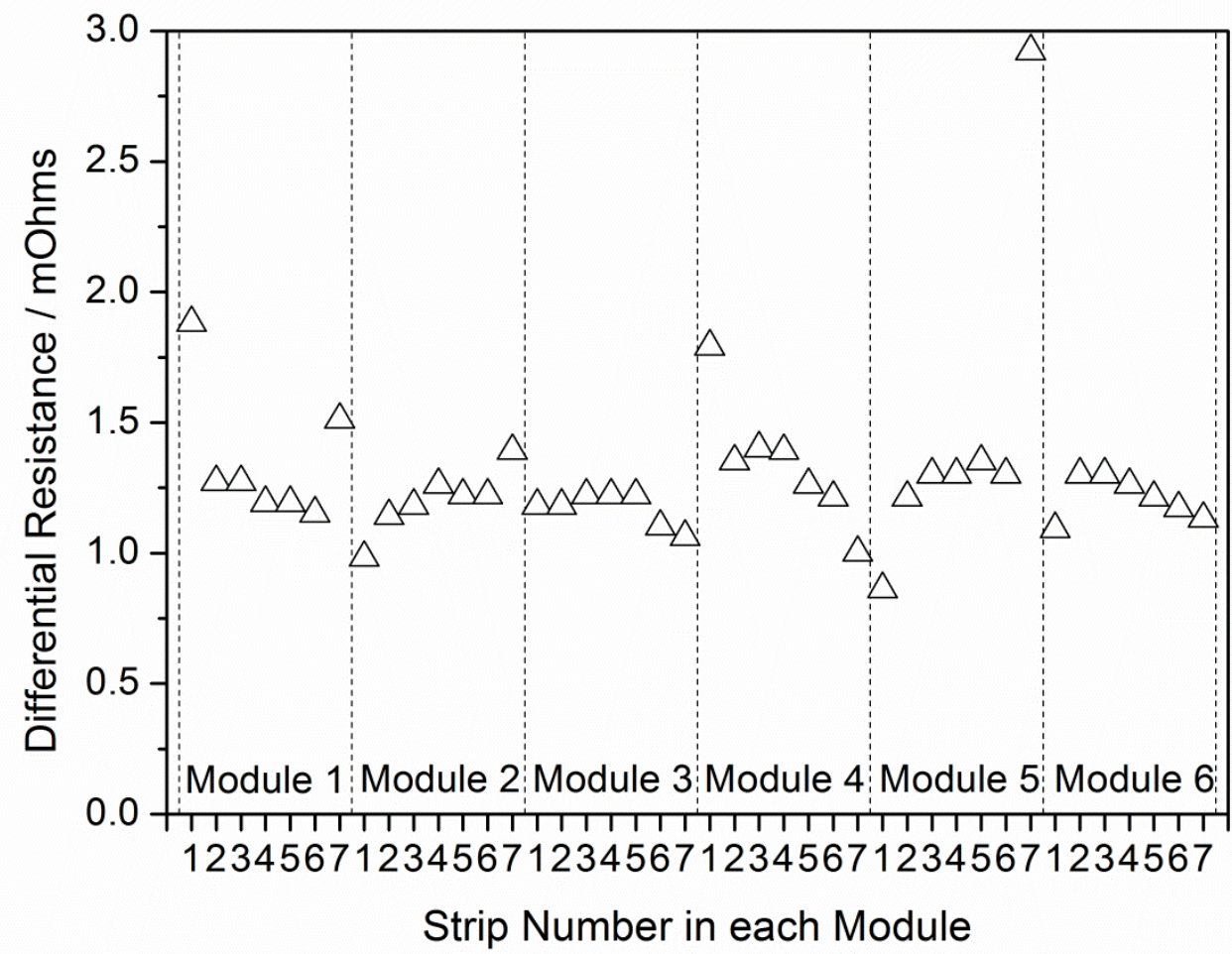

Figure 6: Differential resistance calculated from Figure 5 for all modules during a $\mathbf{3}$ second acceleration test on the dynamometer

\section{b. Continuous discharge tests}

In the continuous discharge test the power was increased to roughly $20 \mathrm{~kW}$ and then slowly decreased until a relatively constant current of roughly 100A per side pod was maintained until a minimum voltage of $2.9 \mathrm{~V}$ was measured in any cell. Small fluctuations in current draw were introduced by the driver attempting to maintain a continuous current. The current and voltage response measured using the BMS is shown in Figure 7. 


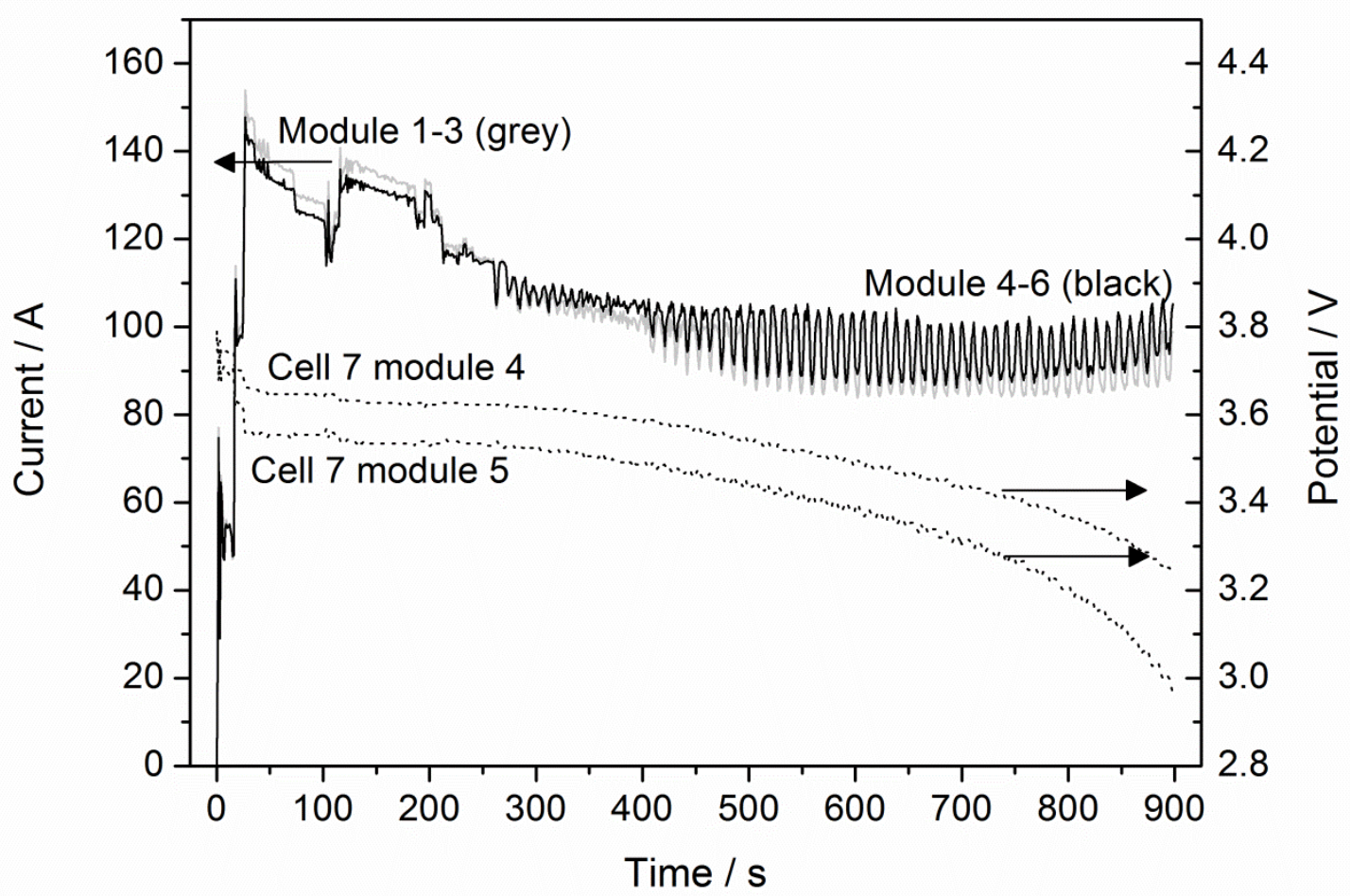

Figure 7: Test data during a 15 minute continuous discharge test on the dynamometer, the voltage response for the strip exhibiting the highest and lowest voltage under load (dotted lines) and the module currents for each side pod (solid lines) is shown

It can be seen in Figure 7 that the difference between the voltage response for the strip exhibiting the highest and lowest voltage under load by the end of the test run is large, with a difference of 269 $\mathrm{mV}$ by the time the vehicle shut down. It is also interesting to note that side pod 2, modules 4-6, initially provides less current, which can be explained if it has a higher internal resistance, than side pod 1, modules 1-3. However, over time the situation reverses and side pod 2 eventually provides more current. This can be explained if it assumed that the state-of charge (SOC) of side pod 1 drops more quickly because of the initially higher current, until the polarisation resistance increases because of the lower state-of-charge. Then the side pods become balanced under load, continually rebalancing themselves in dynamic equilibrium as their state-of-charges drop and their impedances and resistances change. An unforeseen consequence of this is that we expect that after removal of the load, as the side pods are no longer balanced at open circuit, significant currents will flow between the side pods. Unfortunately it was not possible to monitor these currents due to the set up of the vehicle, although a rise in cell temperatures was observed after removing the load.

\section{Identifying the fault cause}

It was hypothesised that the problem with module 5 strip 7 could either be caused by the cells, the module design or assembly. If the problems were caused by the cells then the cells in strip 7 of module 5 should have exhibited significant differences in their performance, which could have been caused either by manufacturing inconsistencies or damage to the cells at some point in their life. If the problems were caused by the module design or assembly then the unequal current paths must 
have been caused by a design flaw or high resistances introduced by substandard module components or contacts.

\section{a. Individual cell testing}

In order to test the first hypothesis that the problems were caused by the cells, the 12 cells from strip 7 of module 12 were individually tested by means of electrochemical impedance spectroscopy (EIS). The OCV at rest of the tested cells were $3.71 \mathrm{~V}$ which corresponded to $60 \%$ of SOC. The EIS spectra were recorded using an Autolab Potentiostat/FRA (Metrohm Inc) between 2000 and $0.1 \mathrm{~Hz}$ in galvanostatic mode with a current amplitude of $100 \mathrm{~mA}$. A typical example EIS spectrum of one of the individual cells and the equivalent circuit used to fit the data is shown in Figure 8.

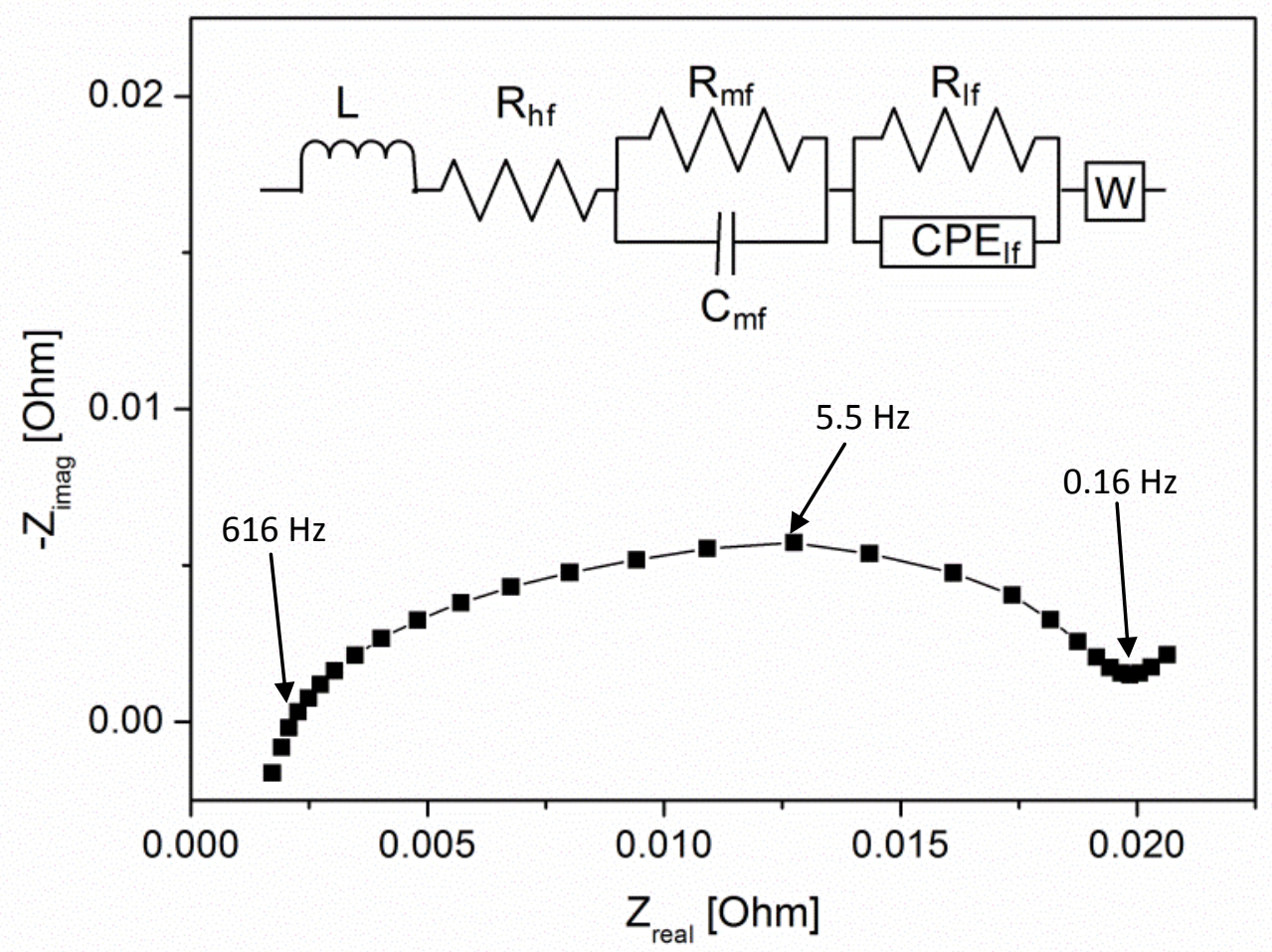

Figure 8: Typical EIS spectrum of the tested lithium polymer battery at OCV of $3.71 \mathrm{~V}$ and the equivalent circuit used to fit the data

Three processes can be distinguished and are fitted: 1) lithium ion transport through the Solid Electrolyte Interface (SEI) layer, 2) charge transfer at the electrode/electrolyte interface and 3) diffusion through a porous media. It is common to use an equivalent circuit comprising of an inductor, resistors, capacitors and so-called constant phase elements to fit the EIS response of an electrochemical device. The constant phase elements are used instead of capacitors when the EIS response in the complex plane represents a semi-depressed circle and have a general form of: $Z_{C P E}=\left(j^{*} Q^{*} \omega\right)^{-P}$ where $Q$ is a capacitance like parameter and $P$ is a power index, usually between 0 and 1 ).

It was found experimentally that for this specific lithium polymer battery the best fit with lowest errors (up to 5\%) can be obtained with the equivalent circuit shown in Figure 8 . The elements of this 
circuit are: high frequency inductor $L$ and high frequency intercept $R_{h f}$ that arise as a result of the electrode and current collector electrical arrangement in the battery and series resistance of the current collectors, electrodes, electrolyte and connector terminals and wires respectively; mid frequency resistance $R_{m f}$ associated with the lithium ion transport through the SEl; low frequency resistance $R_{\mathrm{ff}}$ related to the charge transfer; and generalised Warburg diffusion $\mathrm{W}$ through porous electrodes. The complex non-linear least squares parameter fit was carried out using ZView software (Scribner Inc). Note that $R_{m f}$ and $R_{\mathrm{If}}$ are also known as $R_{\mathrm{SEl}}$ and $\mathrm{R}_{\mathrm{ct}}$ respectively. All the cells had very similar fitted parameters as shown in Figure 9 and the values were well within the ranges expected from the manufacturer's data.
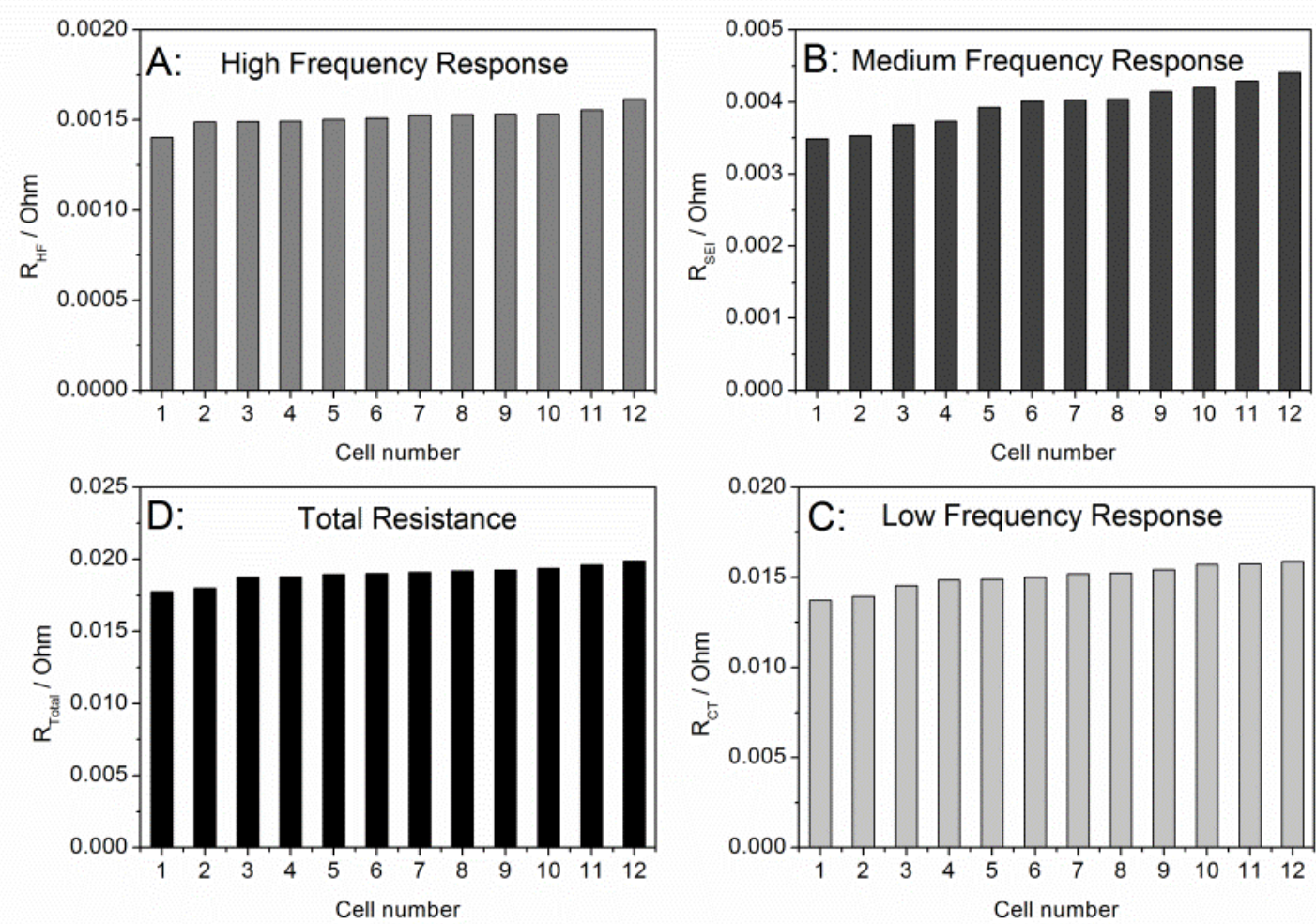

Figure 9: Calculated equivalent circuit parameters for the 12 cells in value ascending order from strip 7 of module 5: A) Series resistance, B) Charge transfer resistance, C) Resistance due to transfer through SEI and D) Total polarisation $\left(\mathbf{R}_{\mathrm{SEI}}+\mathbf{R}_{\mathrm{CT}}\right)$.

As Figure 9 suggests, the differences in various resistances among the cells was not significant enough to cause the measured fault. For example the difference between maximum and minimum values for $R_{H F}, R_{C T}, R_{S E I}$ and $R_{\text {Total }}$ did not exceed $13.5 \%, 14 \%, 20 \%$ or $11 \%$ respectively. It should be noted that the values of series resistance did not indicate any problems as a result of possible corroded contacts, oxidised current collectors or poorly conductive solid polymer electrolyte in the tested cells. Neither did resistances of charge transfer and SEI transport. Hence, the battery module fault was not caused by any of the tested cells. 


\section{b. Modelling}

In order to test the second hypothesis that the problems were caused by the module design or assembly, a model of a battery module was created in Simulink using the SimPowerSystems toolbox. A schematic of the Simulink battery module is shown in Figure 10.

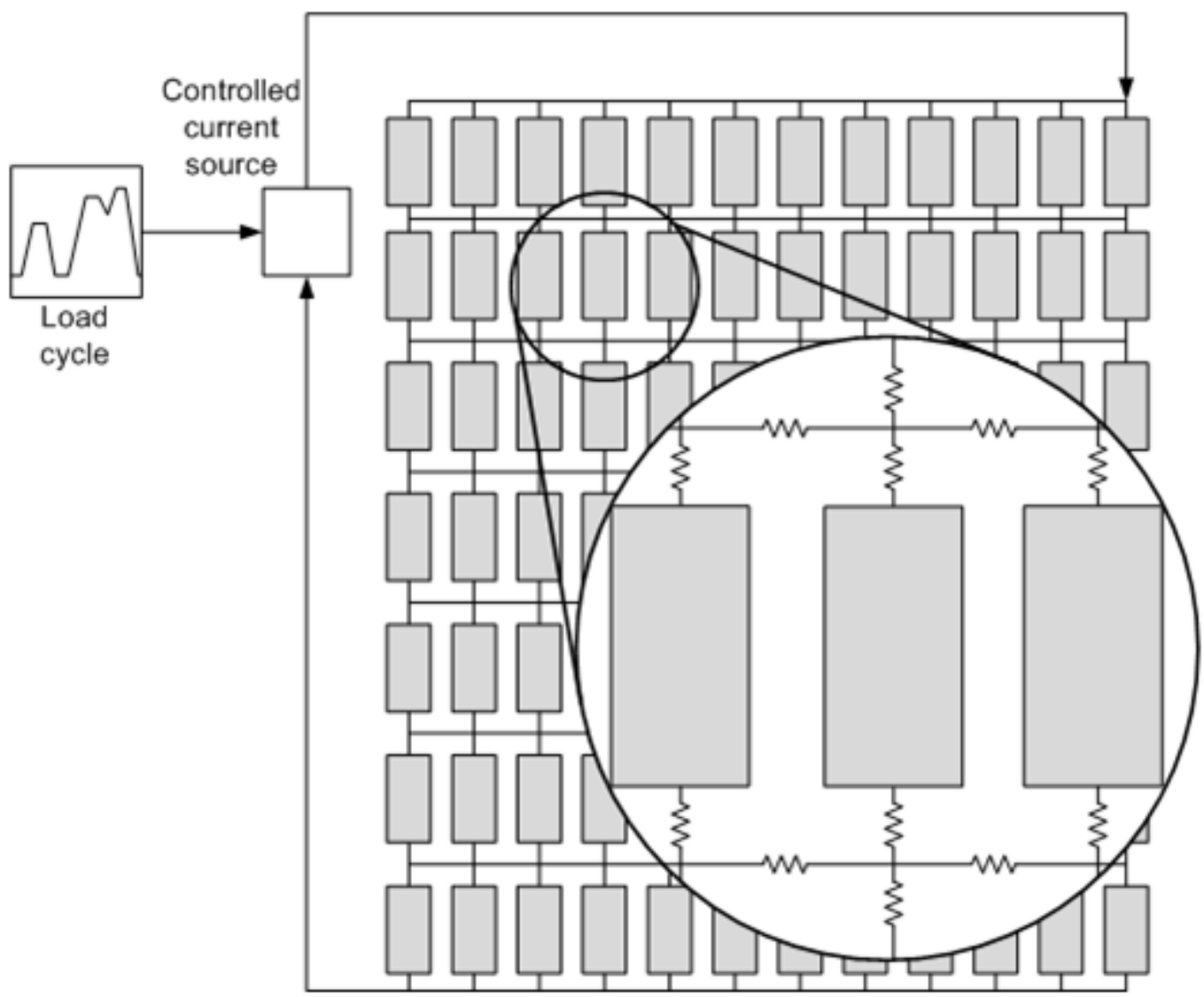

Figure 10: Schematic of the Simulink battery model

Using the Simulink battery model, the cells were arranged in a 12P7S configuration, with electrical connections being made at opposite corners of the module. A controlled current source connected between the positive and negative terminals of the module allowed for the regulation of module current from an inputted load cycle.

Each cell within the simulation was connected to a resistor at both its positive and negative terminals. This represents the contact resistance of the aluminium clamps to the cell tabs. Another resistance was then placed between each set of cells to represent the resistance of the aluminium interconnectors. This model therefore allows for the simulation of the effects of a higher contact resistance.

\section{i. Battery model}

The Simulink SimPowerSystems battery model was used to model the cells in the module. This model is based on a set of semi-empirical relationships and is able to characterise a number of different battery chemistries including: lead-acid, lithium-ion, nickel-cadmium and nickel-metalhydride. The lithium-ion battery model was used. Equation 1 and equation 2 show the semi- 
empirical relationships used to characterise the lithium-ion battery model under charge and discharge conditions.

$E_{\text {discharge }}=E_{0}-K \cdot \frac{Q}{Q-i t} \cdot i^{*}-K \cdot \frac{Q}{Q-i t} \cdot i t+A \cdot \exp (-B \cdot i t)$

Equation 1

$E_{\text {charge }}=E_{0}-K \cdot \frac{Q}{i t+0.1 \cdot Q} \cdot i^{*}-K \cdot \frac{Q}{Q-i t} \cdot i t+A \cdot \exp (-B \cdot i t)$

Equation 2

Where $E_{\text {discharge }}$ and $E_{\text {charge }}$ represent the discharge and charge potentials, $E_{0}$ is the open circuit potential, $K$ is the polarization resistance $(\Omega), Q$ is the maximum battery capacity (Ah), it is the extracted capacity (Ah), $i^{*}$ is the low frequency current dynamics (A), $A$ is an exponential voltage constant $(\mathrm{V})$ and $\mathrm{B}$ is an exponential capacity constant $\left(A h^{-1}\right)$.

By matching the constants in the battery model with that of the measured discharge profiles of the Kokam cells, an acceptable cell polarisation was achieved. The parameters used for the model are shown in Table 2. The discharge curve of the 4.8 Ah Kokam cells, under different C-ratings, and the output of the matched battery model are shown in Figure 11.

Table 2: Battery parameters used for simulations

\begin{tabular}{ll}
\hline Nominal voltage & $3.61 \mathrm{~V}$ \\
Rated capacity & $4.8 \mathrm{Ah}$ \\
Maximum capacity & $4.95 \mathrm{Ah}$ \\
Fully charged voltage & $4.2 \mathrm{~V}$ \\
Nominal discharge current & $4.2 \mathrm{~A}$ \\
Series resistance & $2 \mathrm{~m} \Omega$ \\
Capacity at nominal voltage & $4 \mathrm{Ah}$ \\
Exponential voltage zone & $3.69 \mathrm{~V}$ \\
Exponential capacity zone & $3 \mathrm{Ah}$ \\
\hline
\end{tabular}




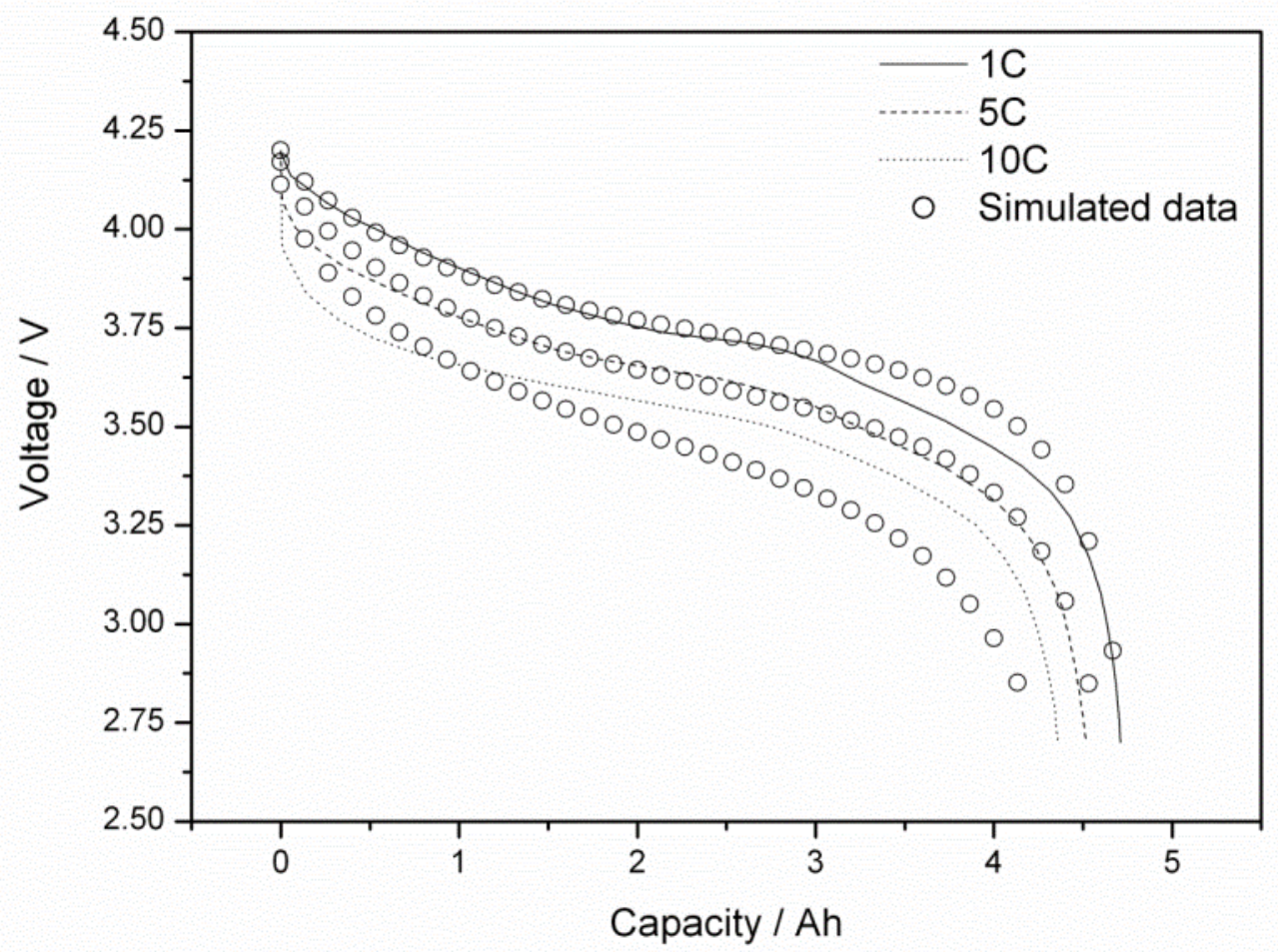

Figure 11: Discharge curve of a Kokam 4.8Ah lithium-polymer cell [from the battery data sheet [16]] compared to simulated data

As shown in Figure 11, under low discharge rates $(<5 C)$ the battery model acceptably replicates the performance of the real cell with a reasonable degree of accuracy. At higher rates of discharge $(>10 C)$ the battery model becomes less accurate, possibly because of temperature effects which are not captured by the model. However, for the purpose of these simulations a discharge rate of $>10 \mathrm{C}$ will not be experienced and therefore this level of accuracy was deemed acceptable.

\section{ii. Comparisons of results}

Using the full battery module model, the current interrupt experiment, as shown in Figure 4, was recreated. Using the drawn current as the input and cell strip voltage measurements from the left side of the module, it was possible to recreate the same voltage characteristics observed by introducing a high contact resistance in the $7^{\text {th }}$ cell strip between the $2^{\text {nd }}$ and $3^{\text {rd }}$ cell of the parallel strip. The nominal interconnect resistance was estimated at being $0.1 \mathrm{~m} \Omega$ and the contact resistance $3 \mathrm{~m} \Omega$. In order to match the current interrupt test voltage measurements the high interconnect resistance was estimated to be $2.5 \mathrm{~m} \Omega$. The simulation results are shown in Figure 12 . 


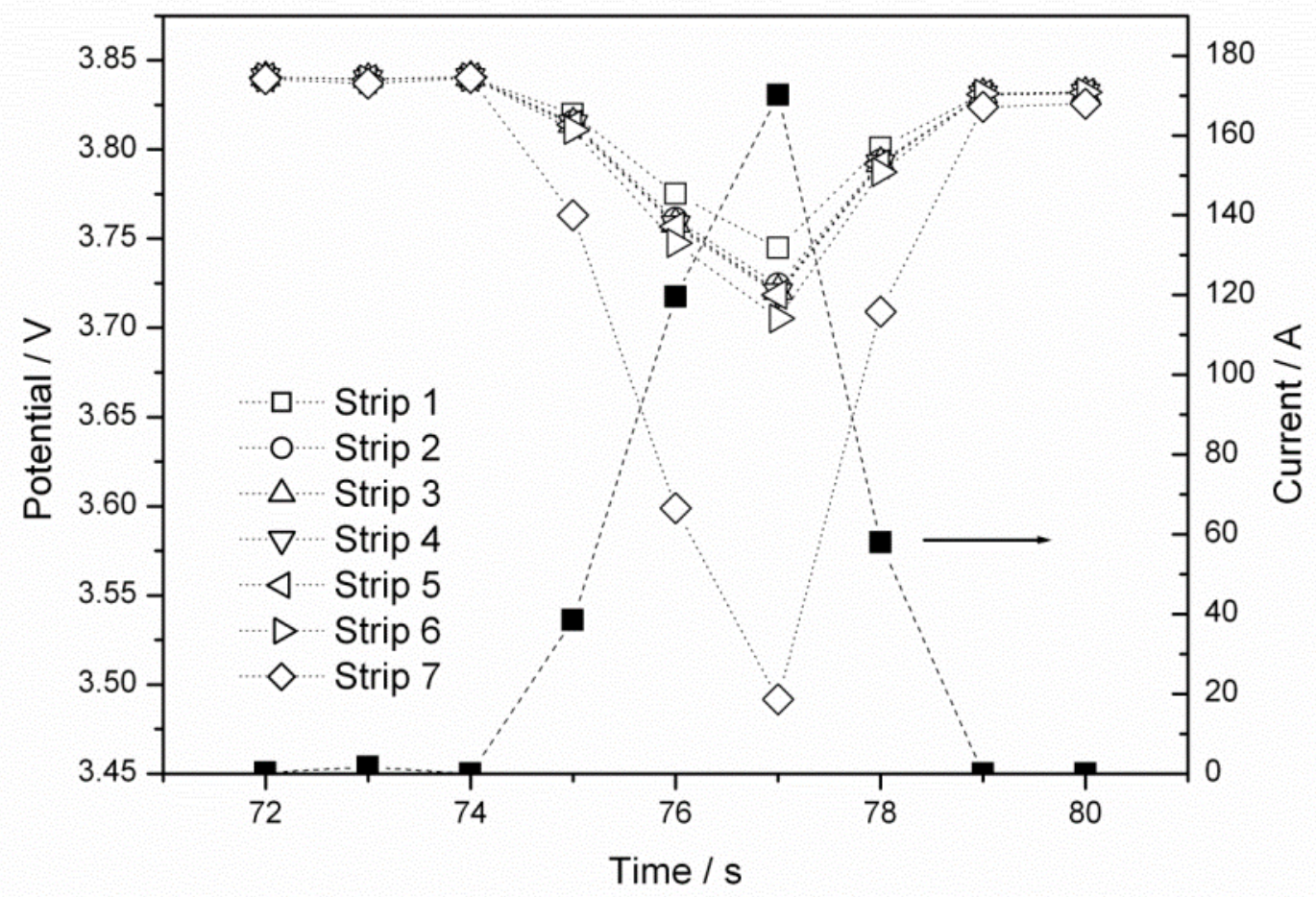

Figure 12: Simulated current interrupt test with high contact resistance based for module 5 during a 3 second acceleration test on the dynamometer, current is shown with the axis on the right (black squares), and the voltage response of each strip of cells is shown with the axis on the left (hollow symbols)

The model was then used to explore the effect of removing the high interconnector resistance, and the results of the current interrupt test were rerun to give the response of the cell with the normal resistance. This is shown in Figure 13. 


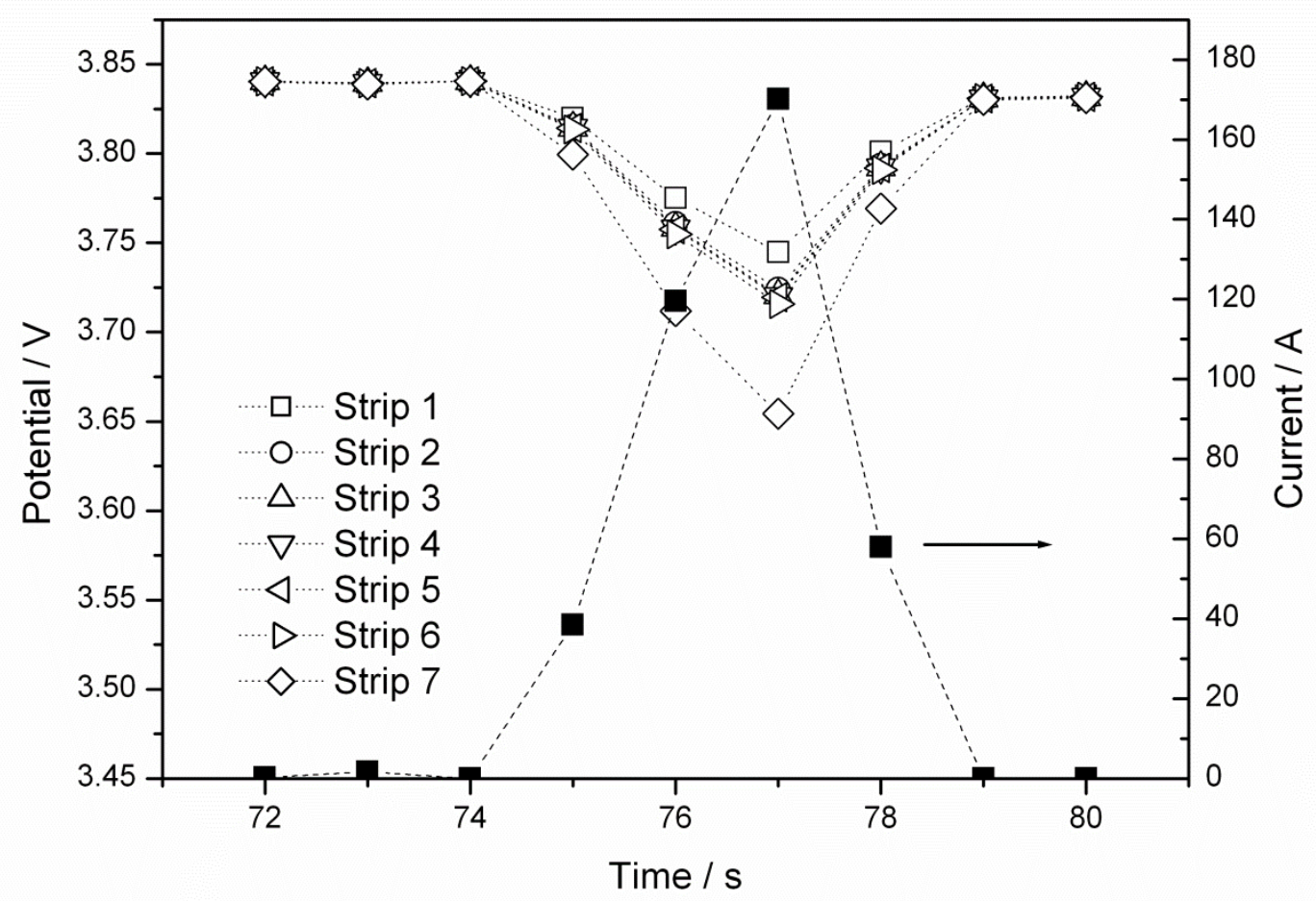

Figure 13: Simulated current interrupt test with resolved contact resistance based for module 5 during a 3 second acceleration test on the dynamometer, current is shown with the axis on the right (black squares), and the voltage response of each strip of cells is shown with the axis on the left (hollow symbols)

As shown in Figure 13, the voltage drop of the $7^{\text {th }}$ strip does not fall as much as in the case where there was a high contact resistance as shown in Figure 12. In the case of Figure 13, it can be seen that even though all the contact resistances are the same there is still a difference in cell voltage, most noticeably, between strip 1 and strip 7. This is caused by the uneven resistance path of the module design between the main terminals. This effect was therefore accentuated in the case of the high contact resistance. Therefore the model supports the hypothesis that there is both a fault caused by a high contact resistance and a flaw as an unintended consequence of the highly parallel design approach.

Comparison of the simulated results in Figure 12 and Figure 13 with the experimental data shown in Figure 4 also indicates the model has very similar performance to the real cells, although the modelling of diffusion is not quite correct. For the present work, however, this does not matter.

By extracting the voltage drops from the model across each cell strip and finding the differential resistance with and without the high contact resistance, the effect of the high contact resistance can be quantified. This is shown in Figure 14. 


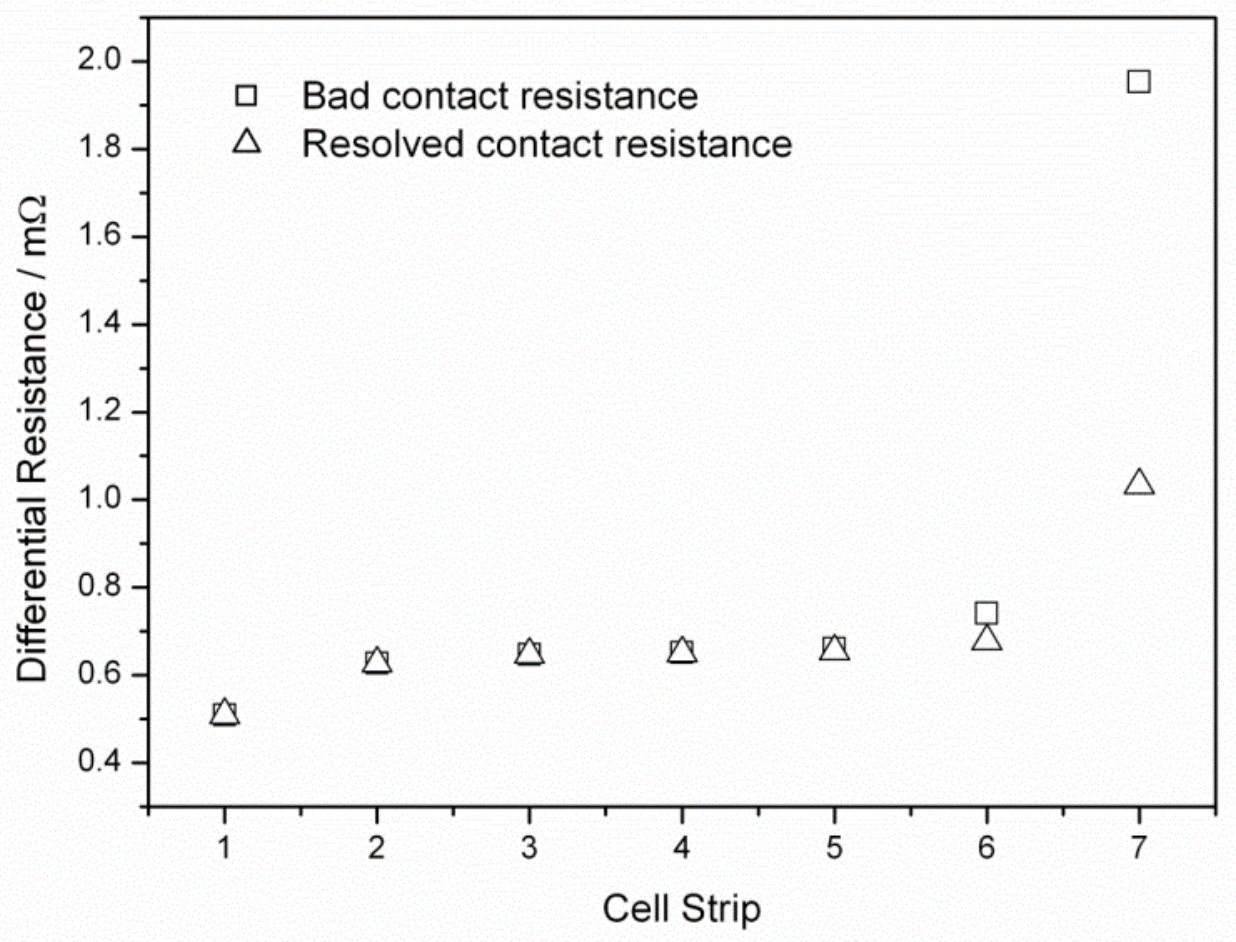

Figure 14: Differential resistance calculated from simulated current interrupt test of module 5 comparing the effects of a bad contact resistance and equal contact resistance

As shown in Figure 14, the presence of the high interconnector resistance leads to a high differential resistance being measured in cell strip 7, where the faulty connection was now suspected. By changing this back to the nominal resistance, the measured differential resistance returns to a normal value. In the case of equal contact resistances there is still an observed differential resistance as discussed earlier.

In the case of Figure 14 the shape of the differential resistance curve across the cell strips is a sideways S-shape. If the electrical connections were made on the same side of the module this would be a U-shaped curve. This effect can be explained using the model. The current drawn from each individual cell was also simulated for the even and uneven contact resistances. Figure 15 shows the current distribution for the module with oppositely connected electrical terminals with even contact resistances for a 150A discharge just after the load has been applied. 


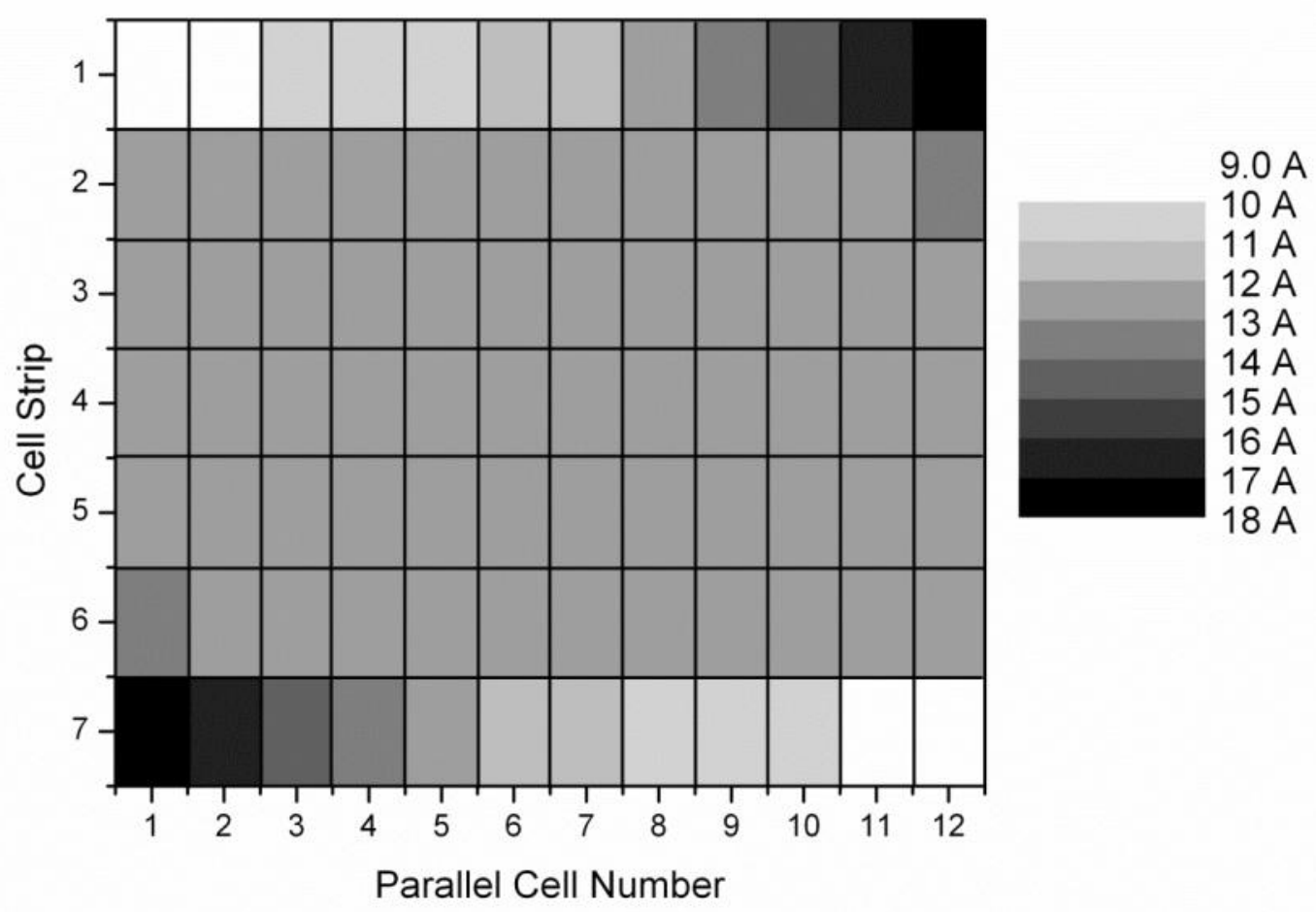

Figure 15: Current distribution in battery module with equal cell contact resistances for a 150A discharge

As shown in Figure 15, the highest observed currents are at the electric connection points at opposite corners of the module, with the highest currents being observed diagonally across the module as this is the path of least resistance. The cells that are at the opposite corner, relative to the electrical connections, experience a much lower discharge current. This effect also occurs when the electrical connection points are on the same side. In the no fault case, the maximum discharge current is still double that of the minimum. This effect therefore leads to cell unbalancing and internal currents flowing when no load is applied. Figure 16, then shows the current distribution in the module with the high interconnection resistance. 


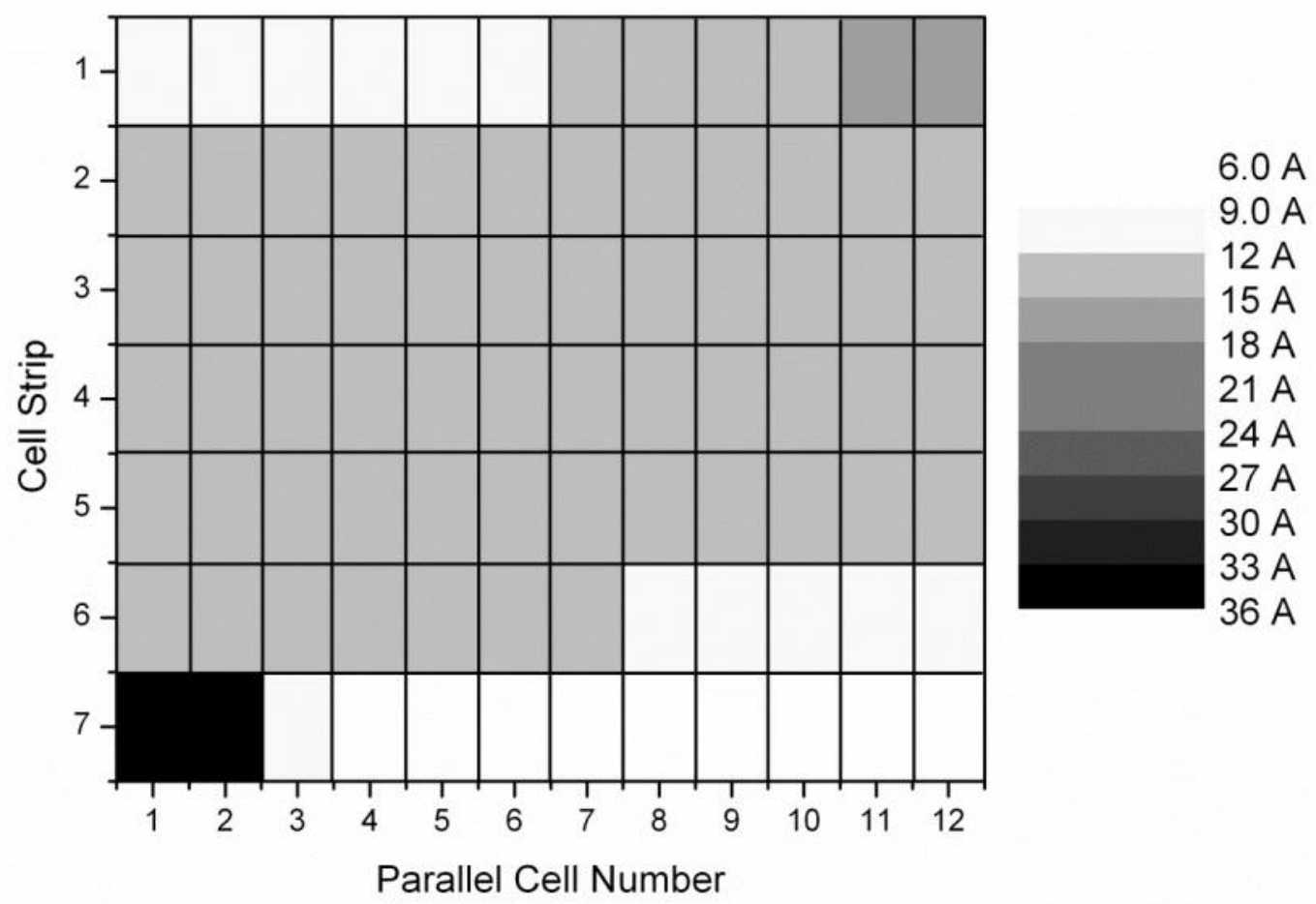

Figure 16: Current distribution in battery module with a bad contact resistance for a 150A discharge

In Figure 16, the uneven current distributions observed in Figure 15 are further accentuated, especially near the location of the high resistance. This high resistance restricts current flow from the cells isolated by the high contact resistance, drastically increasing the load on the cells near the current collection and decreasing the load on the cells isolated by the high contact resistance. Under the same discharge conditions, the model predicts the maximum discharge current to be 6 times that of the minimum discharge current. This highlights the importance of minimising contact resistances and ensuring equal balancing.

\section{Resolving the fault}

The most serious fault was identified to be in module 5 strip 7 , and it was suspected that either a single high contact resistance around cell 9 in the strip was effectively isolating 8 or 9 cells beyond the high contact resistance, or a combination of high resistances were causing a similar effect. This meant that the majority of the current was flowing through 3 or 4 cells nearest the current collection connection, causing the voltage drop across those cells to be significantly higher than in the other cells in that strip. As the BMS was monitoring the voltage across module 5 strip 7 on the same side at the current collection connection, it measured the higher voltage drop and not the lower voltage drop which it would measure if it was connected on the other side. This would give rise to a higher differential resistance measured by the current interrupt.

Therefore, module 5 was partially dismantled, to expose strip 7, and the cell tabs and aluminium clamps were inspected for damage or anything that could cause a high resistance. A thin film of plastic, suspected to be glue, was found to be covering one side of the aluminium clamp between 
cells 8 and 9. The aluminium clamp was cleaned, and the module reassembled, put back in the vehicle, and then data from subsequent vehicle tests was analysed in order to check if the fault had been resolved.

The full vehicle was tested at Dunsfold Aerodrome in Surrey, England, with a fully charged battery pack, and the vehicle was tested until the BMS detected that one of voltage measurements went below $2.5 \mathrm{~V}$ under load, the minimum safe limit for voltage under discharge. The vehicle was subject to a number of test runs simulating the skid-pan and acceleration events at Formula Student, before it was subjected to consecutive 5 minute test runs around a coned off area of the airstrip which had been designed to simulate the endurance event at Formula Student. The results from the first and third test, which was the last test run during which the voltage limit was exceeded and vehicle shut down, are shown in Figure 17 and Figure 18.

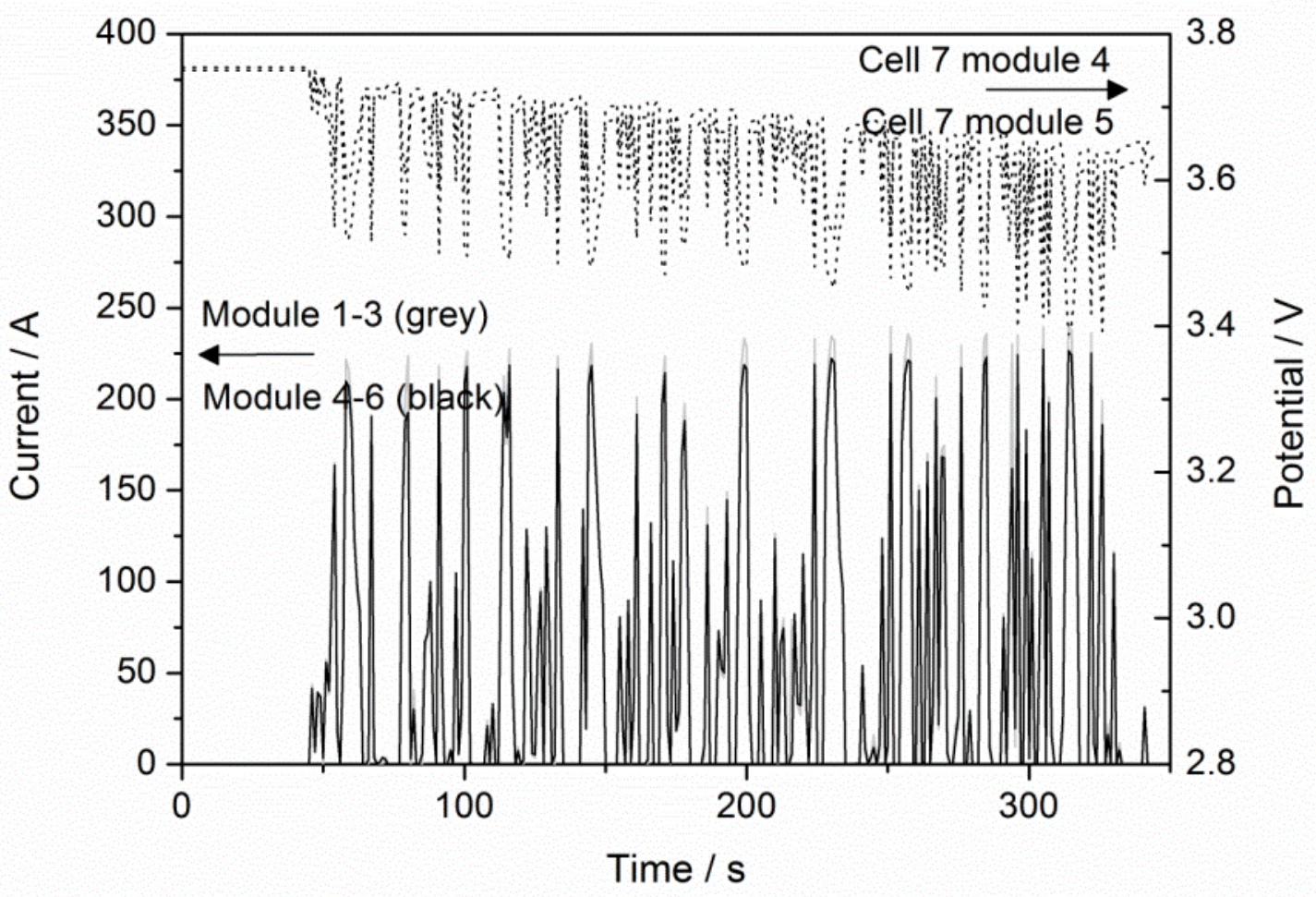

Figure 17: Test data during the first 5 minute endurance test at Dunsfold, the voltage response for the strip exhibiting the highest and lowest voltage under load (dotted lines) and the module currents for each side pod (solid lines) is shown 


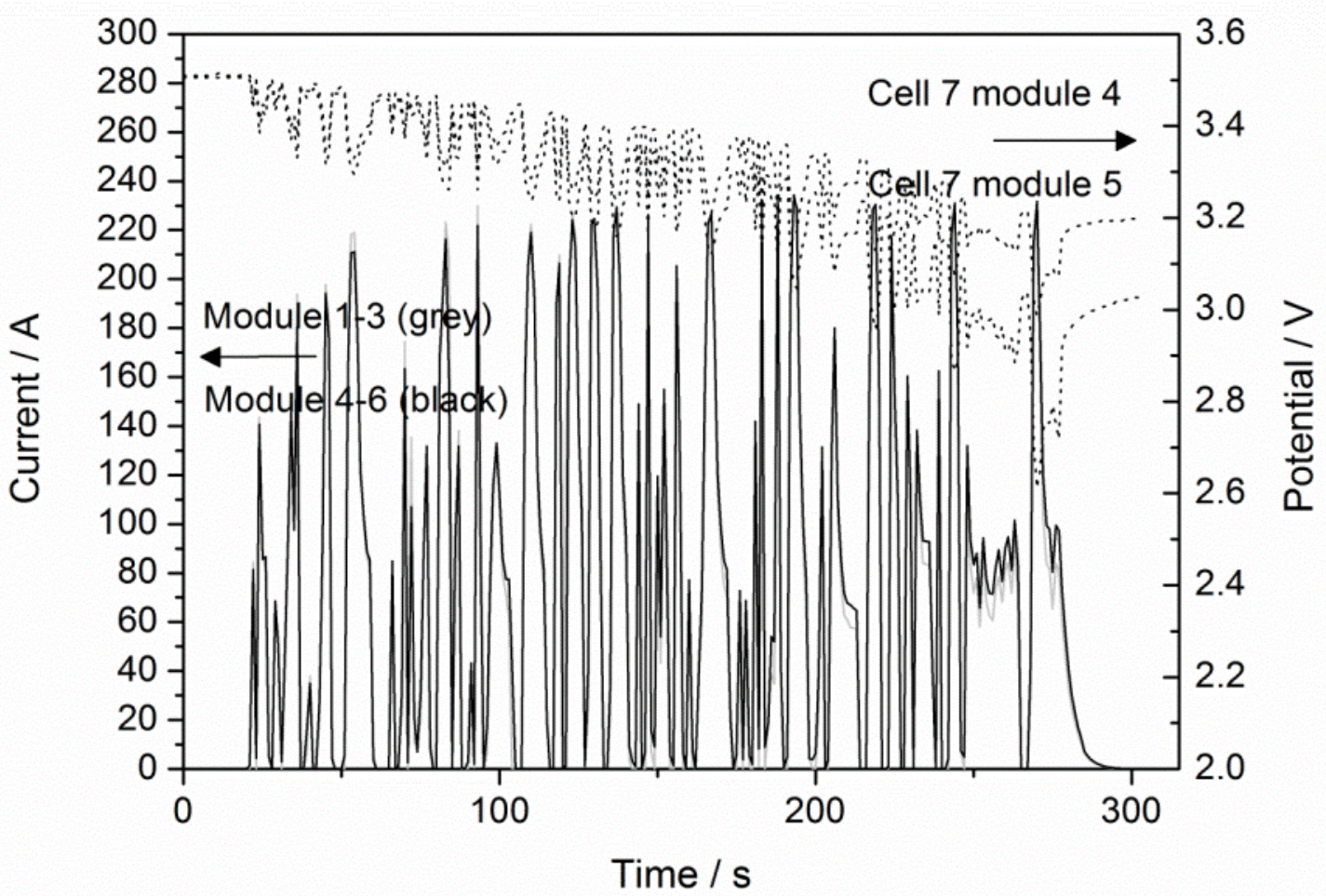

Figure 18: Test data during the third 5 minute endurance performance test at Dunsfold, the voltage response for the strip exhibiting the highest and lowest voltage under load (dotted lines) and the module currents for each side pod (solid lines) is shown

It can be seen in Figure 17 and Figure 18 that significant voltage differences became apparent between strips in different modules towards the end of the final test run, which are explained by the assumption that minor variations in capacity or SOC can have a significant impact upon voltage when cells are heavily discharged. This was because each module had not been completely balanced by the BMS before the vehicle was tested after the modules had been rebuilt. Therefore an inspection of the voltages is not the most appropriate method to determine if the fault had been resolved.

The differential resistances were therefore calculated from an appropriate event in the test cycle, where the current had been interrupted due to a braking event following a high acceleration event, and is shown in Figure 19. 


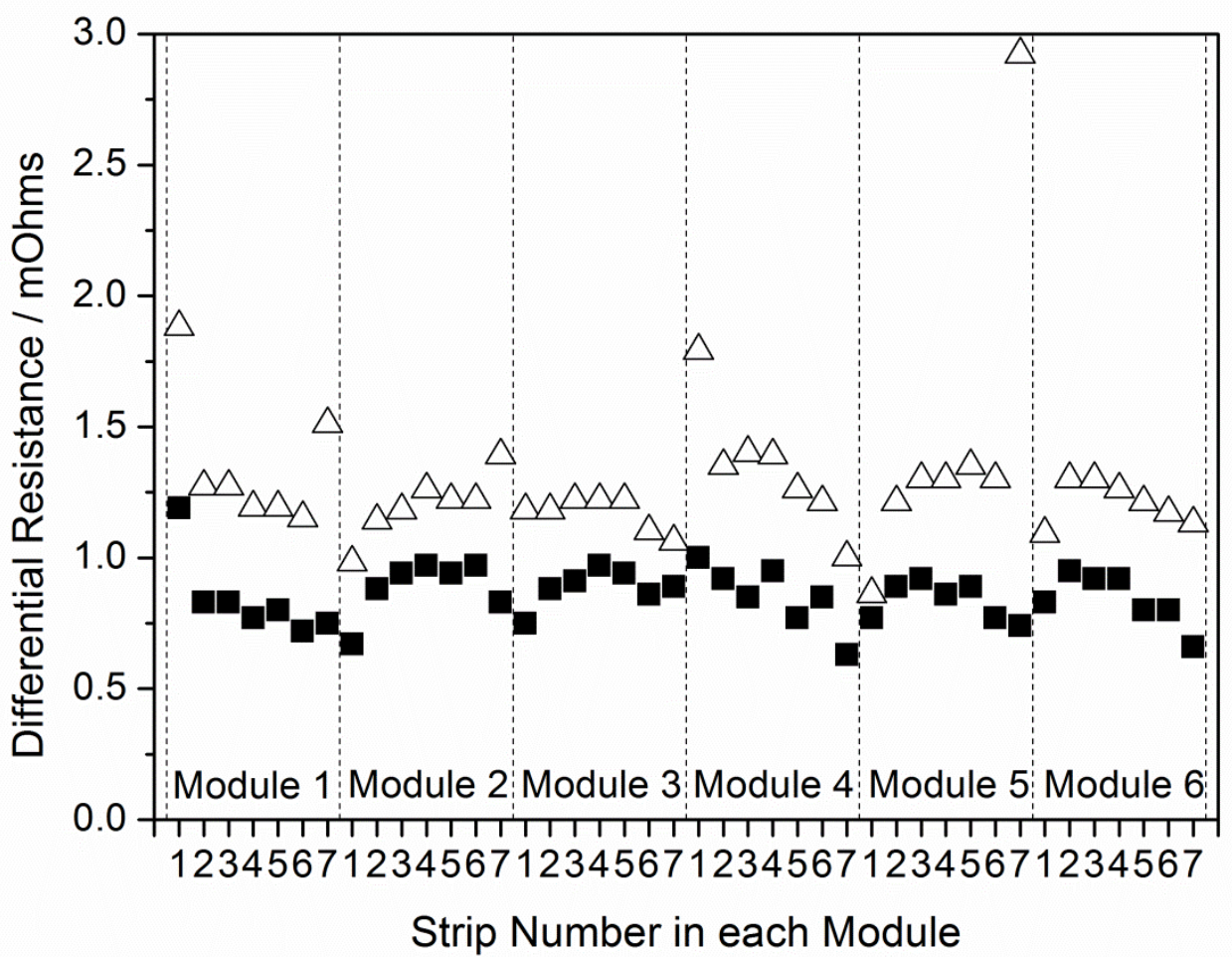

Figure 19: Differential resistance for all modules calculated from a current interrupt event caused by braking during vehicle endurance test run 3 (filled squares), compared to the differential resistance for a $\mathbf{3}$ second acceleration test on the dynamometer before the modules were rebuilt

It can be seen in Figure 19 that the fault has clearly been resolved, that module 5 strip 7 now has a differential resistance that is similar to all the others. The average differential resistance for all the parallel strips is also lower, and this can be explained by the fact that the average temperature of the modules during the third vehicle endurance test run had reached $30^{\circ} \mathrm{C}$ whereas the average temperature of the modules during the 3 second acceleration test on the dynamometer was only $20^{\circ} \mathrm{C}$.

\section{Impact on vehicle performance}

In order to investigate the effect of the fault on the vehicle performance it was possible to use the Simulink battery model to re-run the current profile from the test data from the endurance test runs, both with and without a high contact resistance between cells 8 and 9 in module 5 strip 7 . As the high contact resistance caused the strip voltage for that set of cells to be much lower, this caused the BMS to shut down the vehicle prematurely. Using the model to simulate the same drive cycle without the higher contact resistance, the extra drive time can be calculated, shown in Figure 20. 


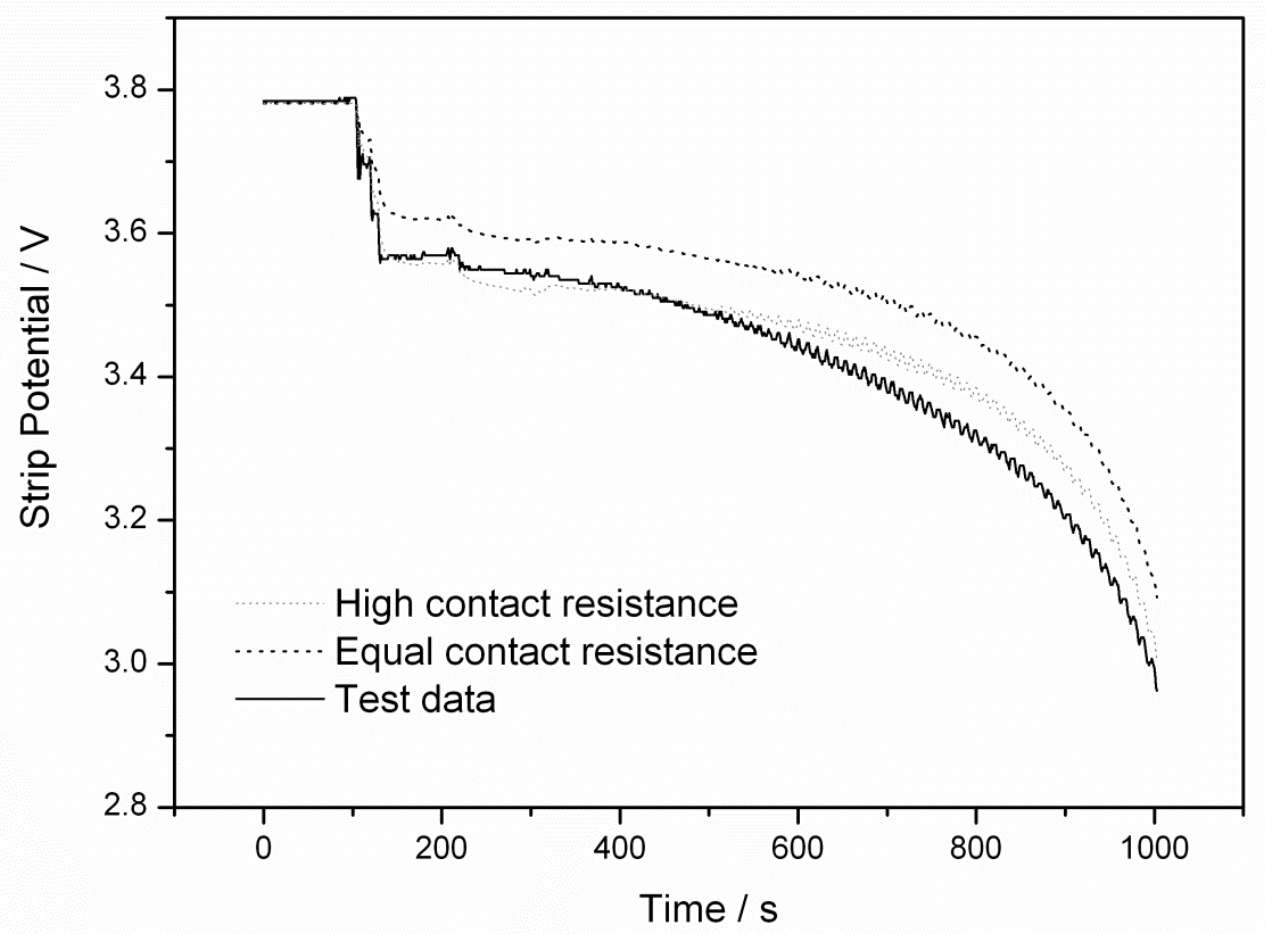

Figure 20: Reconstructed voltages for module 5 strip 7 based upon the endurance test run drive cycle with and without the high contact resistance

As shown in Figure 20, in the case of the high contact resistance the BMS disabled the vehicle when the lowest strip voltage reached $2.9 \mathrm{~V}$. In the case where the contact resistance was resolved, extrapolating the same load cycle the strip voltage would have reached $2.9 \mathrm{~V}$ at a later point meaning that the vehicle run time was reduced because of a single high contact resistance.

\section{Conclusions}

In this paper we have shown that, just as an individual cell may not behave uniformly under high current conditions, so an entire battery pack is also susceptible to non-uniform currents flowing through individual cells when there are parallel strings present in the pack. This is particularly acute under high-C charge or discharge conditions. Even if the impedance of individual cells varies up to $10-20 \%$ this is not a cause of current flow non-uniformity across the battery modules. Instead, it is the interconnection resistances between highly paralleled cells which cause this effect. In the current work, the reason that a highly paralleled design was chosen was because, under the competition rules for the particular vehicle, other configurations would have required the individual monitoring of all 504 cells in each module.

We conclude that battery pack design must consider carefully designs which use highly paralleled strips of cells and also the electrical contact resistances present in the inter-connects between cells, and that anomalously high contact resistances can lead to serious imbalances in the way in which cells are used in the pack, with currents between parallel cells being unequal. A full pack test procedure can be used to identify cell strings which have much higher contact resistances. 
We also conclude that for parallel connected cells there may be significant difference in cell statesof-charge after sustained continuous discharge if the cells are not carefully arranged such that equal currents flow through all of them. Even when equal currents do flow through cells, differences in temperature, voltage and other external and internal conditions across the cells may lead to differences in currents which become worse over time unless active monitoring or balancing is included. Upon returning to quiescent conditions, cells will tend to self-balance until parallel connecting strings have equal voltages. However, this may lead to large currents flowing and temperature increase.

There are some clear implications for the design of battery management and battery monitoring systems in this type of parallel arrangement. First, the BMS voltage sensing must located at side of module where the voltage drop is expected to be worst. Second, an active balancing BMS may need to include a delay before active balancing in order to allow time for passive balancing currents to flow within the pack.

\section{Acknowledgements}

The authors would like to thank all the students and supervisors involved in the Imperial Racing Green project who have been involved in the development of IRG04, the battery electric vehicle described in this paper. In particular the students who were involved in the design, making and testing of the IRG04 battery packs, Aran Kankiwala, Amit Meghani, lan Hunt, Jessica Poore, Alice Rowlands, Aimen Sattar, Patrick White, Shahrukh Akhtar, Canupsorn Chairatna, Hassan Joudi, Lisheng Lu, Ashley Throop, Jielai Zhang, Ahmad Faiz Bakri, Chee Chung Lee, Shiang Jin Chin, Tian Yi Yuen, Yeit Hau Chin, David Topham, David Zhong, Thea Cooper and Rob Carter, and the supervisors who helped manage the students, Fred Marquis, Dave Robb, Graham Gosling, Paul Mitcheson, Finn Giuliani and Richard Silversides.

The authors would also like to thank the sponsors and supporters of Imperial Racing Green. In particular those who provided parts or sponsorship related to the development of the IRG04 battery packs, ABSL, Dow Kokam, and REAP Systems.

\section{References}

[1] J. Gomez, R. Nelson, E.E. Kalu, M.H. Weatherspoon, J.P. Zheng, Journal of Power Sources, 196 (2011) 4826-4831.

[2] H. Vaidyanathan, W.H. Kelly, G. Rao, Journal of Power Sources, 93 (2001) 112-122.

[3] C. Forgez, D.V. Do, G. Friedrich, M. Morcrette, C. Delacourt, Journal of Power Sources, 195 (2010) 2961-2968.

[4] R.E. Gerver, J.P. Meyers, Journal of the Electrochemical Society, 158 (2011) A835-A843.

[5] U.S. Kim, C.B. Shin, C.-S. Kim, Journal of Power Sources, 180 (2008) 909-916.

[6] J. Remmlinger, M. Buchholz, M. Meiler, P. Bernreuter, K. Dietmayer, Journal of Power Sources, 196 (2011) 5357-5363.

[7] K. Takeno, M. Ichimura, K. Takano, J. Yamaki, S. Okada, Journal of Power Sources, 128 (2004) 6775.

[8] K. Smith, C.-Y. Wang, Journal of Power Sources, 160 (2006) 662-673.

[9] M.W. Verbrugge, Aiche Journal, 41 (1995) 1550-1562. 
[10] T.M. Bandhauer, S. Garimella, T.F. Fuller, Journal of the Electrochemical Society, 158 (2011) R1R25.

[11] R. Spurrett, C. Thwaite, A. Holland, D. Lizius, G. Dudley, Modelling of highly-parallel lithium-ion batteries, in: A. Wilson (Ed.) Proceedings of the Sixth European Space Power Conference, 2002, pp. 685-691.

[12] P.G. Balakrishnan, R. Ramesh, T.P. Kumar, Journal of Power Sources, 155 (2006) 401-414.

[13] V. Yufit, P. Shearing, R.W. Hamilton, P.D. Lee, M. Wu, N.P. Brandon, Electrochemistry Communications, 13 (2011) 608-610.

[14] M.W. Verbrugge, R.S. Conell, Journal of the Electrochemical Society, 149 (2002) A45-A53.

[15] A. Jossen, Journal of Power Sources, 154 (2006) 530-538.

[16] in, Kokam Co., Ltd., pp. Cell Specification Data SLPB 11043140H

http://www.kokam.com/product/product pdf/rc 11070226/SLPB11043140H 11044800mAh Grad e.pdf 11043130/11043111/11042011. 